Check for updates

Cite this: RSC Adv., 2019, 9, 23096

Received 1st May 2019

Accepted 9th July 2019

DOI: $10.1039 / c 9 r a 03268 a$

rsc.li/rsc-advances

\title{
Protective effects of macamides from Lepidium meyenii Walp. against corticosterone-induced neurotoxicity in PC12 cells $\uparrow$
}

\author{
Zejun Yu, (DD ${ }^{\text {ab }}$ Wenwen Jin, (D) *ab Yajie Cui, (D) ab Mingzhang Ao, ${ }^{\text {ab } H a o ~ L i u, ~}{ }^{\text {ab }}$ \\ Hang $X u$ iD ab and Longjiang $Y u$ iD *ab
}

\begin{abstract}
Maca has attracted considerable attention owing to its neuroprotective effects in vitro and vivo. Macamides, a series of nonpolar and long-chain fatty acid $\mathrm{N}$-benzylamides, are considered unique constituents in maca. This study investigated the protective effects of ethanol extracts of maca (EEM) and macamides on corticosterone-induced (CORT) neurotoxicity in rat pheochromocytoma (PC12) cells. CORT reduced cell viability and increased LDH release, intracellular ROS levels, and MMP decline rate, and induced mitochondrial apoptosis. However, pretreatment with EEM and macamides ameliorated CORT-induced neurotoxicity. EEM increased the cell viability and reduced the LDH release. M 18:1, M 18:2, and M 18:3 increased cell viability and reduced LDH release and intracellular ROS generation. M 18:2 and M 18:3 inhibited MMP reduction and reduced the Bax/Bcl-2 ratios. M 18:1 reduced the intracellular ROS without affecting other factors. Moreover, M 18:3 prevented CORT-induced mitochondrial apoptosis, restrained the expression levels of pro-apoptotic proteins, namely, Bax, cytochrome C, cleaved-caspase-3, and cleaved-PARP, and increased the expression levels of $\mathrm{Bcl}-2$. In addition, M 18:3 increased Akt phosphorylation and the ability of M 18:3 to protect against CORT-induced cytotoxicity was remarkably reduced by LY294002, a PI3K phosphorylation inhibitor. M 18:3 also elevated the phosphorylation of CREB and activated the BDNF protein levels in CORT-induced PC12 cells. In conclusion, macamides, especially M 18:3, exert protective effects on CORT-induced PC12 cells. The cellular mechanism of $M$ 18:3 against CORT-induced cytotoxicity may involve inhibition of mitochondrial apoptosis, and activation of Akt and CREB phosphorylation. Overall, macamides may potentially treat neuronal damage induced by CORT.
\end{abstract}

\section{Introduction}

Chronic stress damages central neurons and causes nervous system disorders, such as depression, anxiety disorder, Alzheimer's disease, and Parkinson's disease. ${ }^{\mathbf{1}}$ Under normal circumstances, the hypothalamic-pituitary-adrenal (HPA) axis controls the production of CORT, which exhibits a negative feedback regulation effect on the HPA axis. However, when the negative feedback is inhibited by chronic stress associated with multiple social factors, the HPA axis is dysregulated and overactivated. Thus, CORT continues to increase. ${ }^{2,3}$ Increased CORT can damage the nervous system, induce

anstitute of Resource Biology and Biotechnology, Department of Biotechnology, College of Life Science and Technology, Huazhong University of Science and Technology, 1037 Luoyu Road, Wuhan, 430074, China.E-mail: jww@hust.edu.cn; yulongjiang@hust. edu.cn; Fax: +86 2787792265; Tel: +862787792264

${ }^{b}$ Key Laboratory of Molecular Biophysics, Ministry of Education, Wuhan, 430074, China

$\dagger$ Electronic supplementary information (ESI) available. See DOI: 10.1039/c9ra03268a neurobiochemical changes in the brain, and cause chronic neurodegenerative diseases. ${ }^{1}$ High levels of CORT can cause pathological damage to hippocampal neurons in vitro and vivo, ${ }^{3-5}$ activate differentiated proteins, and induce apoptosis. ${ }^{\mathbf{4}, \mathbf{6}, 7}$ Neuronal apoptosis is induced by CORT by several mechanisms, including the mitochondrial apoptosis pathway, ${ }^{8}$ endoplasmic reticulum stress, ${ }^{9}$ extracellular signal-regulated kinase 1 or 2 pathway, ${ }^{6}$ CREB protein pathway, ${ }^{10}$ and phosphoinositide 3-kinase/protein kinase $\mathrm{B}$ (PI3K/Akt) pathway. ${ }^{\mathbf{1 1}}$ The PC12 cell line is derived from a transplantable rat pheochromocytoma, and large amounts of catecholamine, dopamine, norepinephrine, and CORT receptors are expressed in PC12 cells. Thus, PC12 cells exposed to CORT are widely used to study the neuronal damage associated with chronic stress. ${ }^{\mathbf{1 , 1 2}}$

Maca (Lepidium meyenii Walp.) is a cruciferous plant that has been used as a functional food for centuries because of its high nutritional value and health benefits. ${ }^{13-15}$ Maca and its extracts exert various physiological activities such as anti-oxidative, ${ }^{\mathbf{1 6}}$ anti-fatigue, ${ }^{17}$ and anti-osteoporotic effects, ${ }^{18}$ promote spermatogenesis, ${ }^{19}$ treat menopausal symptoms, ${ }^{20}$ and especially improve depression symptoms, ${ }^{21-23}$ improve cognitive 
function, ${ }^{24}$ and prevent memory impairment. ${ }^{25-27}$ Maca lipophilic extract containing macamides has shown neuroprotective effects against middle cerebral artery occlusion in vivo and $\mathrm{H}_{2} \mathrm{O}_{2}$ injury in vitro. ${ }^{28,29}$ Macamides, a series of nonpolar and long-chain fatty acid $N$-benzylamides, are considered as unique constituents in maca, ${ }^{30,31}$ exhibiting various biological activities, including anti-oxidative, antifatigue, and anti-osteoporotic activities, ${ }^{32-34}$ and activities related to improving the nervous system. Macamides are acetylcholinesterase (AChE) inhibitors. ${ }^{35}$ AChE can hydrolyze acetylcholine (ACh), and ACh deficiency was observed in patients with Alzheimer's disease. Inhibition of AChE is still a strategy for treating Alzheimer's disease. The AChE inhibitors play key roles in anti-inflammatory, anti-oxidant, and antiapoptotic effects. ${ }^{36}$ Moreover, macamides are fatty acid amide hydrolase (FAAH) inhibitors, ${ }^{37-39}$ which can potentially treat inflammation and neurodegenerative diseases. ${ }^{\mathbf{4 0 , 4 1}}$ FAAH inhibitors play a neuroprotective role by increasing endogenous anandamide to activate CB1, and prevent neuronal death in vitro and vivo. ${ }^{\mathbf{4 2 - 4 4}}$ Recently, two papers have reported the neuroprotective effects of macamides. Zhou et al. reported that macamides protected against the dopaminergic neuron loss treated with 1-methyl-4-phenyl-1,2,3,6-tetrahydropyridine (MPTP) in zebrafish through the inhibition of AChE. ${ }^{35}$ Gugnani et al. reported that macamides exerted neuroprotective effects by binding to cannabinoid receptors 1 (CB1) in manganese (Mn)-induced U-87 MG glioblastoma cells. ${ }^{32}$ However, neuroprotective and anti-apoptotic effects of macamides against CORT-induced injury in PC12 cells remain unclear. Moreover, the liposolubility could make it easier for macamides to cross the blood-brain barrier and act within the central nervous system. ${ }^{28}$ Furthermore, chemical drugs such as fluoxetine and clozapine can protect against CORT-induced cytotoxicity in PC12 cells, ${ }^{\mathbf{4 5}, 46}$ but they exhibit hepatotoxicity (high doses of fluoxetine), ${ }^{\mathbf{4 7}}$ myotoxicity, ${ }^{\mathbf{4 8}}$ and hematopoietic toxicity. ${ }^{49}$ Therefore, researchers have focused on developing low-toxic and effective drugs from abundant medical herb resources. In addition, although many monomers exert neuroprotective effects, they need to be chemically synthesized or extracted and purified by complex techniques, which is inconvenient. Ethanol extracts are relatively easy to obtain. Our results showed that EEM also exerted neuroprotective effects in CORT-induced PC12 cells.

M 18:1, M 18:2, and M 18:3 (Fig. 1A) are the most representative and typical macamides. Thus, in this study, we hypothesize that the three macamides could counteract CORT-induced cytotoxicity. The effects of three macamides on CORT-induced cytotoxicity were compared. ROS levels, mitochondrial membrane potential (MMP) decline, mRNA and expression levels of Bax and Bcl-2 were determined. It was found that $\mathrm{M}$ 18:2 and $M$ 18:3 possessed significant protective effects. However, based on the expression levels of Bax and Bcl-2, M 18:3 was chosen to investigate the effects on pro-apoptotic proteins and pro-survival proteins in order to further reveal macamides' neuroprotective mechanisms.

\section{Materials and methods}

\subsection{Materials}

Macamides (batch number 20171212 ; $\geq 98 \%$ purity as determined by HPLC) were purchased from Huashite (Wuhan, China). CORT (batch number 103A031, purity $\geq 98 \%$ ) was obtained from Solarbio (Beijing, China). FBS, HS, penicillin, and streptomycin were acquired from Gibco (Grand Island, USA). DMEM was provided by HyClone (GE, USA). The primary antibodies were obtained from Cell Signaling (CST, USA), Affinity Biosciences (Cincinnati, OH, USA), Abcam (Cambridge, UK), and Servicebio (Wuhan, China). All secondary antibodies were supplied by Servicebio (Wuhan, China).

\subsection{Preparation of ethanol extract of maca (EEM)}

Dried hypocotyls of maca were obtained from Lijiang BaiSuiFang Biotechnology Development Co. Ltd. (Yunnan, China). They were ground into a powder and passed through an 80mesh sieve to obtain maca powder. Dried maca powder (10 g) was soaked in $100 \mathrm{ml}$ of $95 \%$ ethanol $(1 / 10, \mathrm{w} / \mathrm{v})$ and refluxextracted at $70{ }^{\circ} \mathrm{C}$ for $2 \mathrm{~h}$ twice. The extract was collected, filtered, and evaporated with a rotary evaporator at $50{ }^{\circ} \mathrm{C}$ to yield $1.97 \mathrm{~g}$ of EEM. To identify the active ingredients in EEM, we used a chromatographic technique. HPLC experiments comprised an UltiMate3000 system equipped with a UV-vis
A

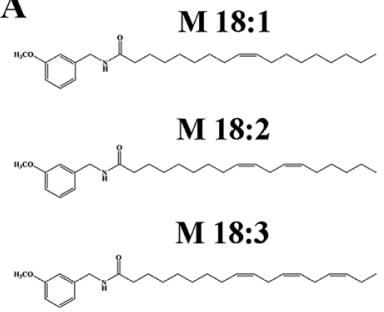

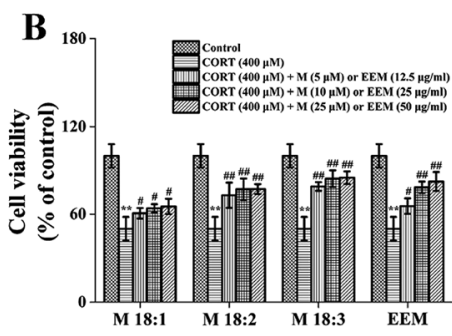

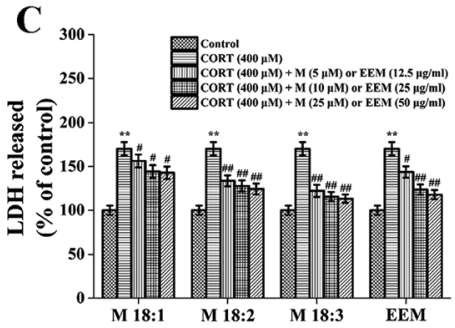

Fig. 1 Neuroprotective effects of macamides (M 18:1, M 18:2, and M 18:3) and ethanol extract of maca (EEM) against CORT-induced injury in PC12 cells. (B) Effects of macamides $(5-25 \mu \mathrm{M})$ and EEM $\left(12.5-50 \mu \mathrm{g} \mathrm{m}^{-1}\right)$ on CORT-induced $(400 \mu \mathrm{M})$ cell death in PC12 cells. (C) Effects of macamides $(5-25 \mu \mathrm{M})$ and EEM $\left(12.5-50 \mu \mathrm{g} \mathrm{ml}^{-1}\right)$ on LDH leakage in CORT-treated $(400 \mu \mathrm{M}) \mathrm{PC} 12$ cells. Results are expressed as mean \pm SEM of six independent experiments. ${ }^{* * P}<0.01$ vs. control group; ${ }^{\#} P<0.05$ and ${ }^{\# \#} P<0.01$ vs. CORT group. CORT: corticosterone. (A) Chemical structures of $\mathrm{N}$-(3-methoxybenzyl)-9Z-octadecenamide (M 18:1), N-(3-methozybenzyl)-(9Z,12Z)-octadecadienamide (M 18:2), and N-(3methozybenzyl)-(9Z,12Z,15Z)-octadecatrienamide (M 18:3). 


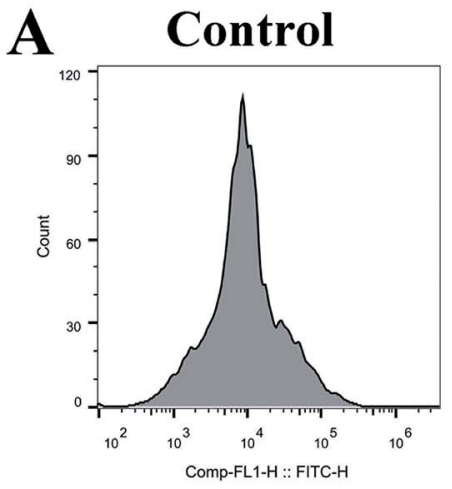

CORT+ M 18:2

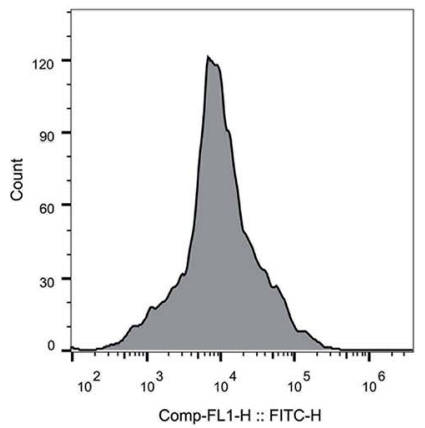

B

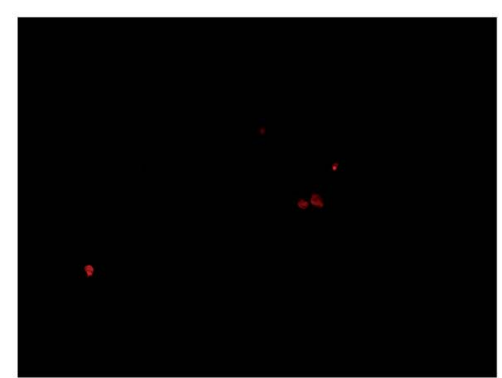

CORT + M 18:2

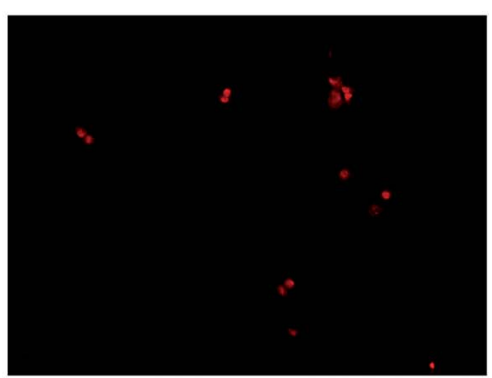

CORT

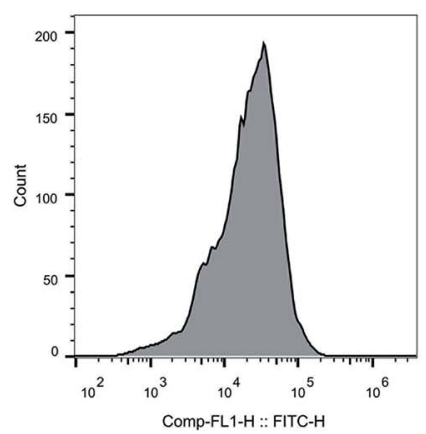

CORT+ M 18:3

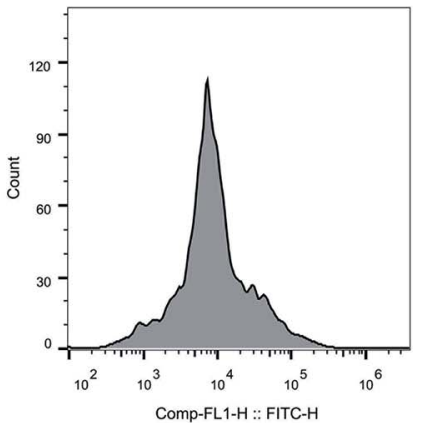

CORT

CORT + M 18:3

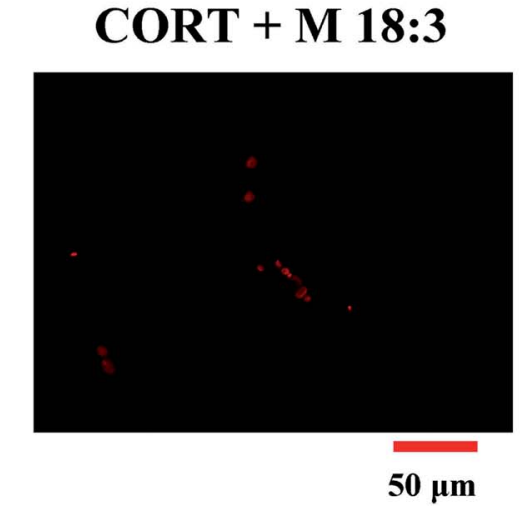

$50 \mu \mathrm{m}$
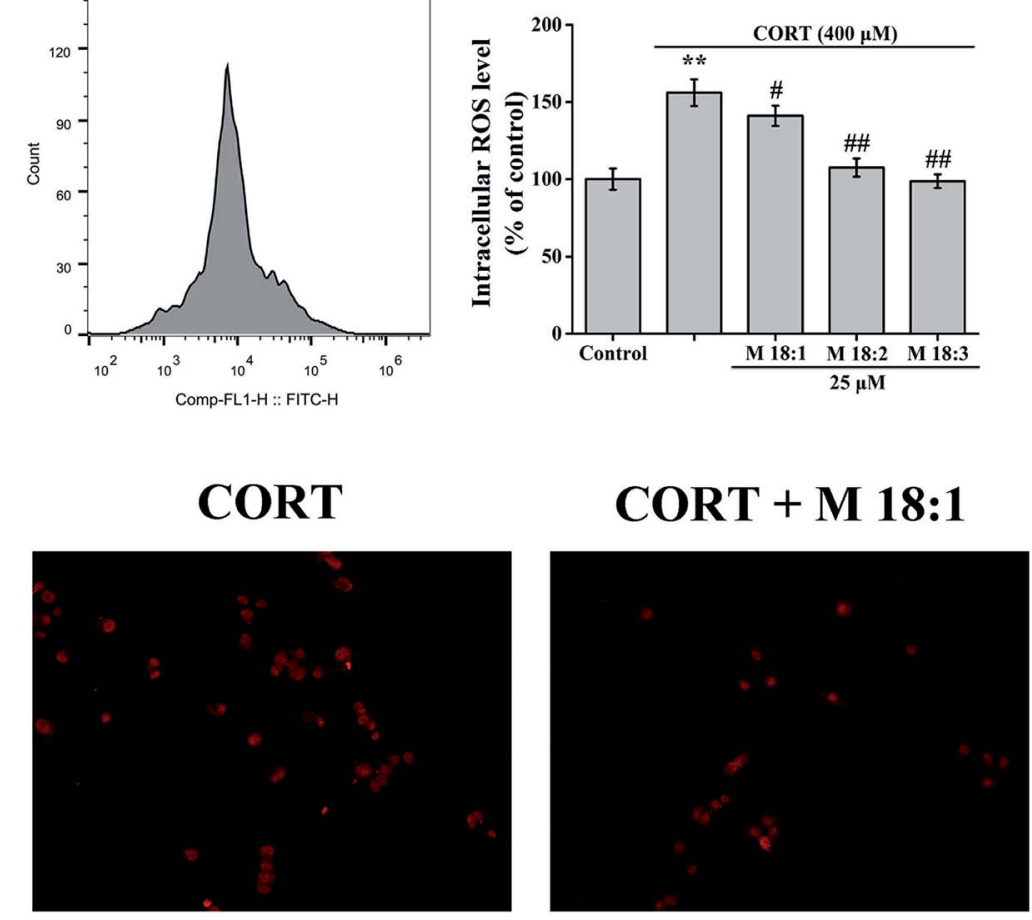

CORT + M 18:1
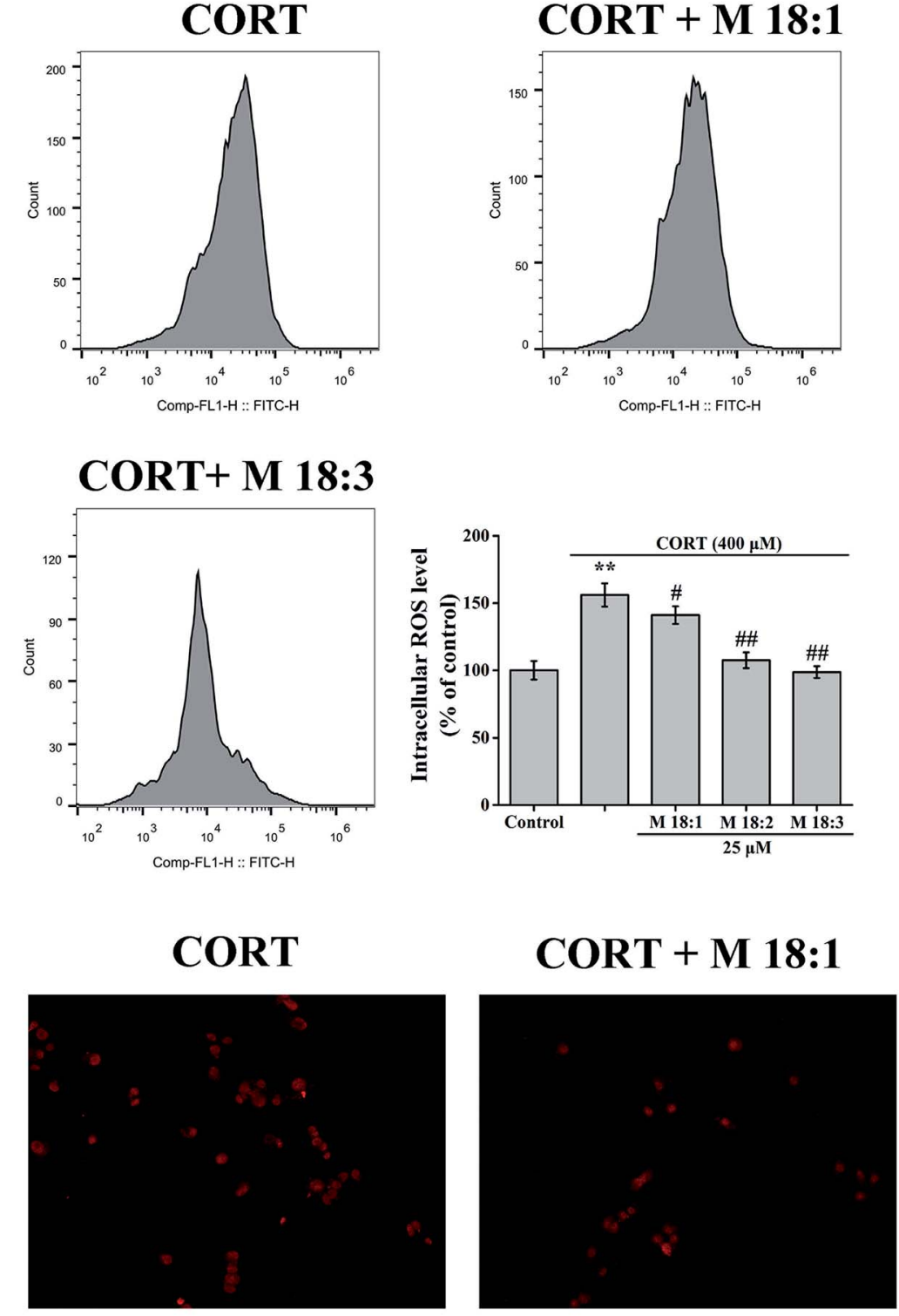

Fig. 2 Effects of macamides (M 18:1, M 18:2, and M 18:3) (25 $\mu$ M) on intracellular ROS levels in CORT-induced PC12 cells. (A) The bar chart describes ROS production. (B) DCFH-DA staining for intracellular ROS. Results are represented as mean \pm SEM of four independent experiments. $* * P<0.01$ vs. control group; ${ }^{\#} P<0.05$ and ${ }^{\# \#} P<0.01$ vs. CORT group. CORT: corticosterone. 
detector. Separation was performed using a C18 column $(250 \mathrm{~mm} \times 4.6 \mathrm{~mm} \times 5 \mu \mathrm{m}$, Waters Sunfire $)$ at $30{ }^{\circ} \mathrm{C}$. The mobile phase was $90 \%$ acetonitrile with a flow rate of 0.6 $\mathrm{mL} \min ^{-1}$. EEM was dissolved using an appropriate volume of methanol and was filtered through a $0.45 \mu \mathrm{m}$ syringe filter. The extract with an injection volume of $20 \mu \mathrm{L}$ was added to HPLC vials and injected into the automatic sampler, and was detected at $210 \mathrm{~nm}$. Macamides were qualitatively identified by comparing the retention times with the standards, and their contents were calculated based on the peak area. By HPLC analysis, the extract contained $750.23 \mathrm{mg} / 100 \mathrm{~g}$ total macamides.

\subsection{Cell culture and treatment}

PC12 cells were cultured using the method described by Ruile Pan. ${ }^{50}$ PC12 cells obtained from the Cell Bank of the Chinese Academy of Sciences (Shanghai, China) were routinely incubated in DMEM (high glucose) supplemented with 10\% FBS, 5\% $\mathrm{HS}$, penicillin $\left(100 \mathrm{U} \mathrm{ml}^{-1}\right)$, and streptomycin $\left(100 \mu \mathrm{g} \mathrm{ml}^{-1}\right)$ at

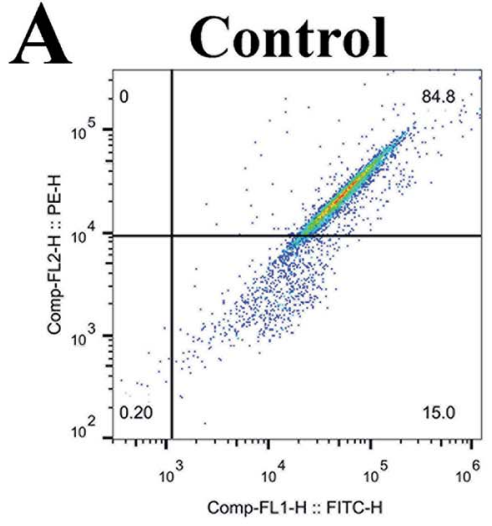

CORT + M 18:2

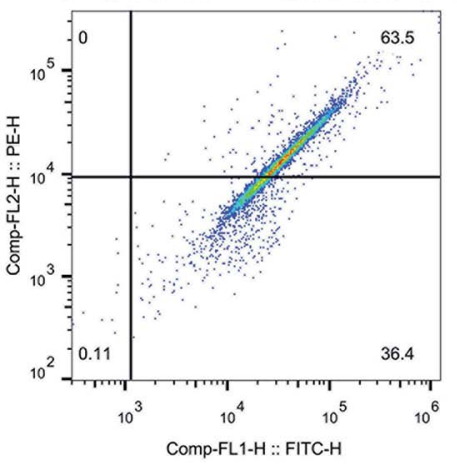

B

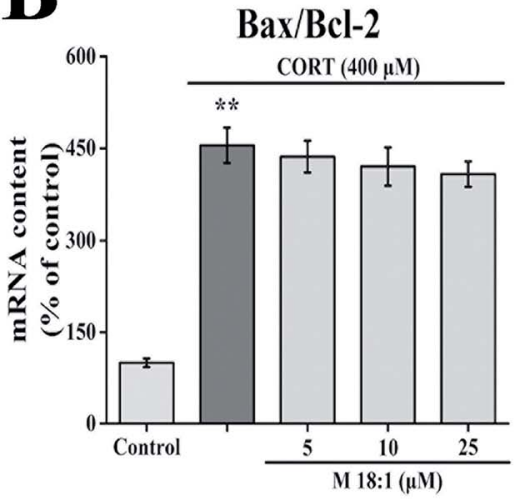

CORT

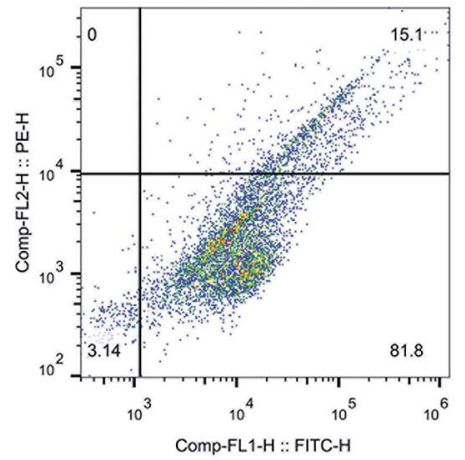

CORT + M 18:3
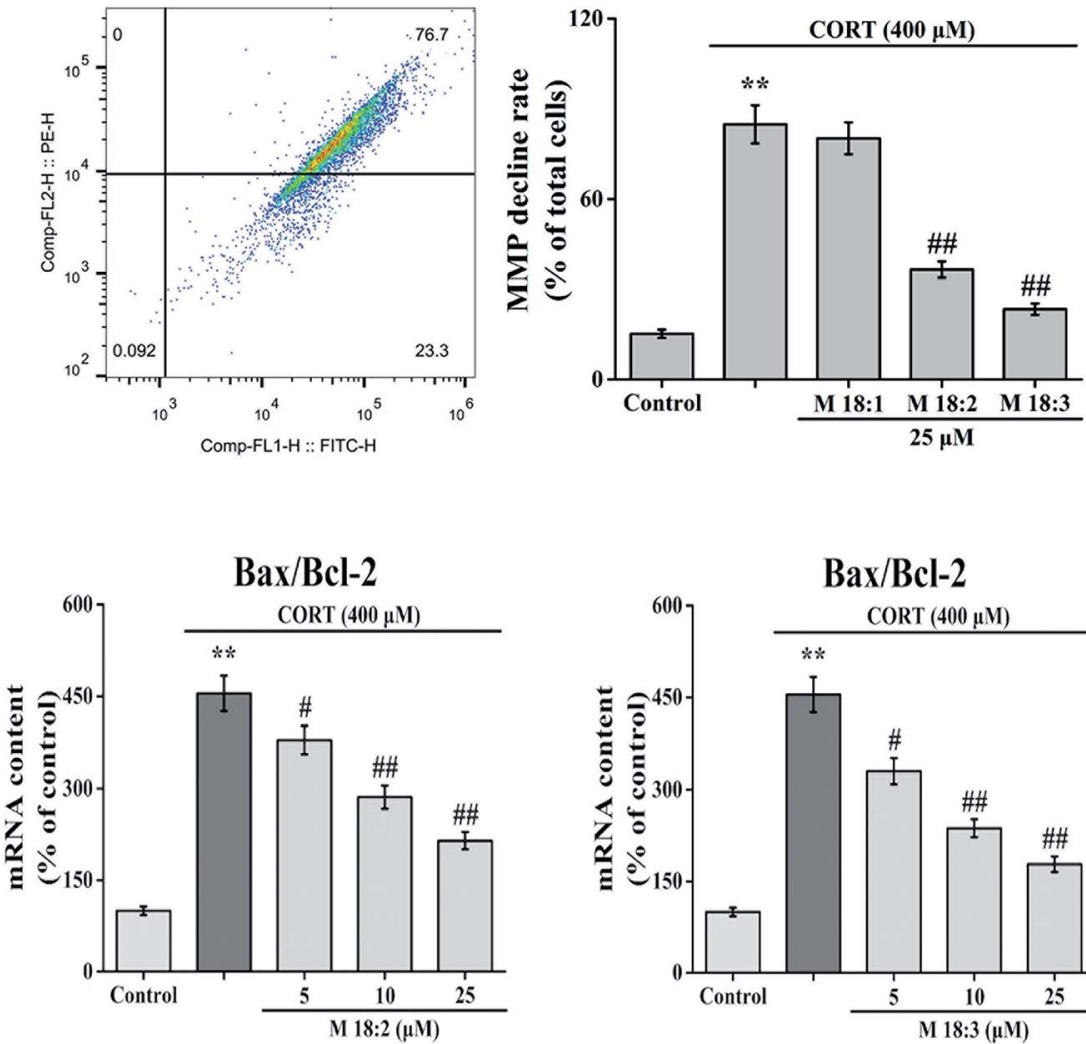

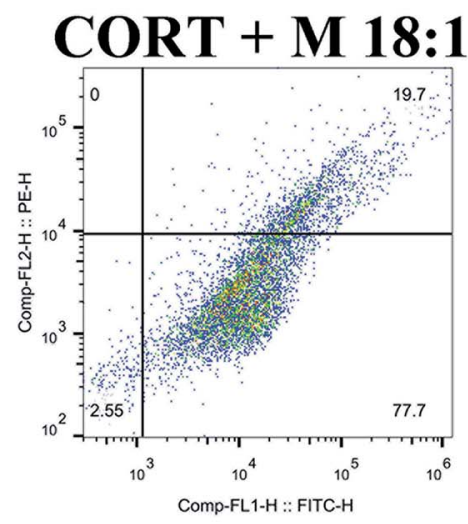

$5 \mu \mathrm{M}$

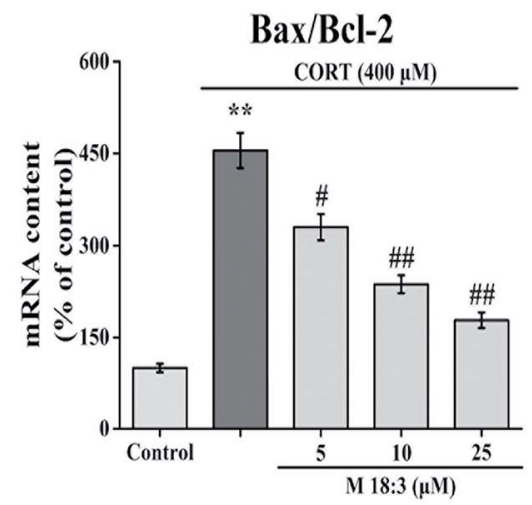

Fig. 3 Effects of macamides (M 18:1, M 18:2, and M 18:3) on MMP depolarization and mRNA levels of Bax/Bcl-2 in CORT-induced PC12 cells. The bar chart of the deterioration of MMP (A) and the mRNA levels of Bax/Bcl-2 (B). Results are represented as mean \pm SEM of four independent experiments. ${ }^{* *} P<0.01$ vs. control group; ${ }^{\#} P<0.05$ and ${ }^{\# \#} P<0.01$ vs. CORT group. CORT: corticosterone. 
$37{ }^{\circ} \mathrm{C}$ in a humidified atmosphere of $95 \%$ air and $5 \% \mathrm{CO}_{2}$. Cells in the exponential growth phase were used for every experiment. EEM, macamides, and CORT were dissolved in dimethylsulfoxide (DMSO) and then diluted with medium to various concentrations. The final concentration of DMSO was less than $0.1 \%(\mathrm{v} / \mathrm{v})$. In order to determine the working concentrations of CORT in PC12 cells, the survival rate of PC12 cells was measured with MTT after incubation with different concentrations of CORT $(50,100,200,400$, and $800 \mu \mathrm{M})$ for $24 \mathrm{~h}$ (Fig. S1 $\dagger$ ). To determine the protective effects of EEM and macamides on CORT-induced cytotoxicity, PC12 cells were divided into the following groups: untreated control, $400 \mu \mathrm{M}$ CORT, $400 \mu \mathrm{M}$ CORT plus EEM $\left(12.5,25\right.$, and $\left.50 \mu \mathrm{g} \mathrm{ml}^{-1}\right)$, and $400 \mu \mathrm{M}$ CORT plus macamide $(5,10$, and $25 \mu \mathrm{M})$. The treatments were conducted $24 \mathrm{~h}$ after the cells were seeded. EEM and macamides were applied $1 \mathrm{~h}$ prior to the treatment with $400 \mu \mathrm{M}$ CORT. The cells were then co-incubated with macamides and CORT for another $24 \mathrm{~h}$.

\subsection{Cell viability}

The cell viability was determined by MTT assay. PC12 cells $(2 \times$ $10^{4}$ cells per well) were seeded into 96 -well plates. After treatment of cells with $400 \mu \mathrm{M}$ CORT at $37{ }^{\circ} \mathrm{C}$ for $24 \mathrm{~h}$ in the presence or absence of various concentrations of macamides or EEM, the solution of MTT was added, incubated for $4 \mathrm{~h}$ at $37^{\circ} \mathrm{C}$, and treated with DMSO for 15 min at $37^{\circ} \mathrm{C}$ to dissolve the formazan crystals. Absorbance was determined at $570 \mathrm{~nm}$ using a microplate reader (BioTek, USA).

\subsection{LDH release}

The LDH release was assessed by a commercial assay kit. PC12 cells $\left(1 \times 10^{5}\right.$ cells per well $)$ were seeded in 24 -well plates. After treatment of cells with $400 \mu \mathrm{M}$ CORT at $37^{\circ} \mathrm{C}$ for $24 \mathrm{~h}$ in the presence or absence of various concentrations of macamides or EEM, the supernatant was incubated with $\mathrm{NADH}$ and 2,4-dinitrophenylhydrazine at $37{ }^{\circ} \mathrm{C}$ for $15 \mathrm{~min}$, respectively. Then, $\mathrm{NaOH}$ was added to stop the reaction. The harvested cells were homogenized to determine the intracellular LDH activity. The amount of $\mathrm{LDH}$ released was measured by a microplate reader $(440 \mathrm{~nm})$.

\subsection{Intracellular ROS level}

Intracellular accumulation of ROS was measured after staining cells with DCFH-DA. PC12 cells $\left(5 \times 10^{5}\right.$ cells per well) were seeded in 6-well plates. After incubation with $25 \mu \mathrm{M}$ macamides for $1 \mathrm{~h}$, the cells were then co-incubated with $25 \mu \mathrm{M}$ macamides plus $400 \mu \mathrm{M}$ CORT for $24 \mathrm{~h}$. The cells were harvested, washed with PBS, and then incubated with DCFH-DA (Beyotime, China, $10 \mathrm{mM}$ for DCFH-DA) at $37{ }^{\circ} \mathrm{C}$ for $30 \mathrm{~min}$ in the dark. After incubation, the cells were washed with PBS and then analyzed
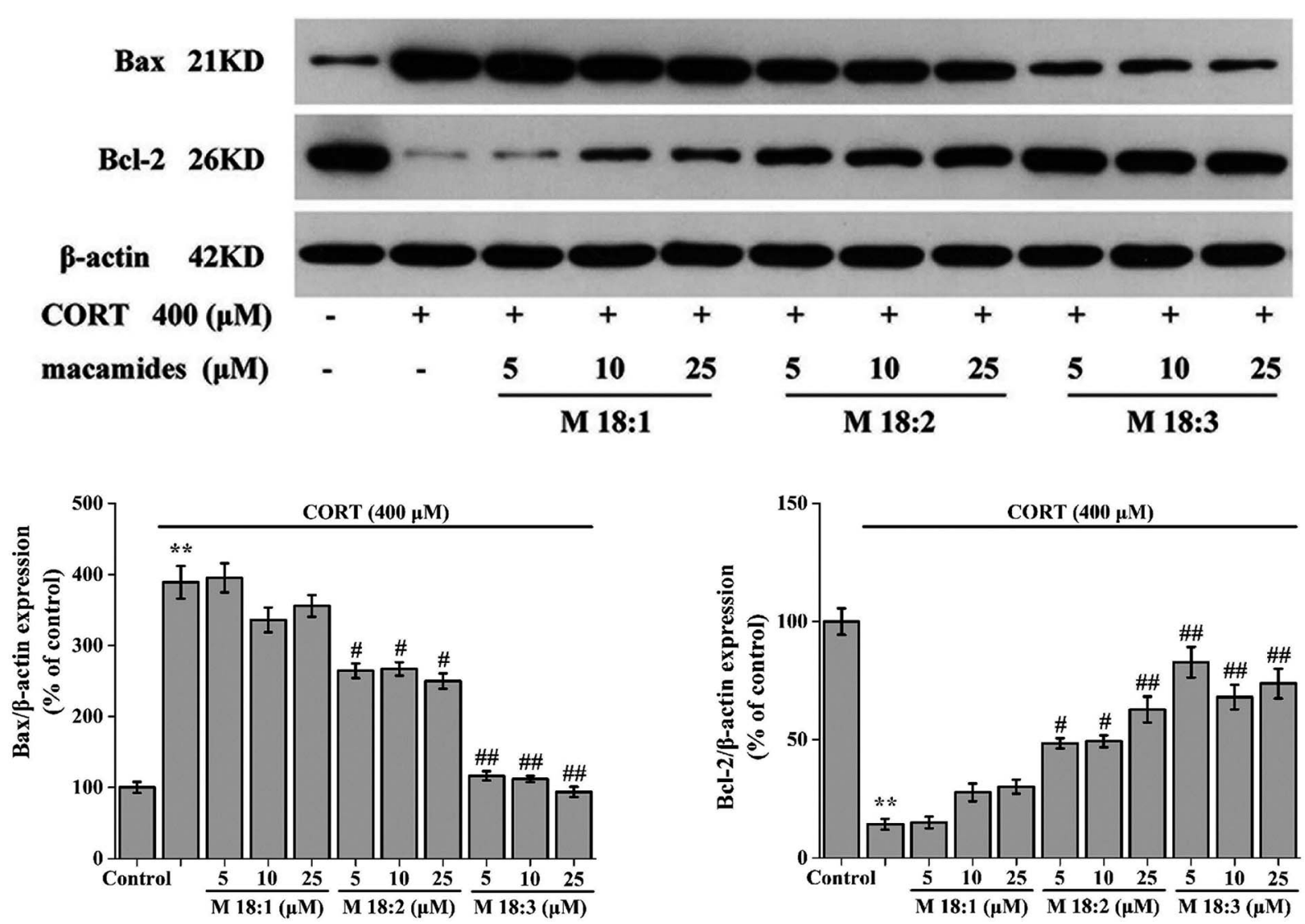

Fig. 4 Effects of macamides (M 18:1, M 18:2, and M 18:3) on the expression levels of Bax and Bcl-2 in CORT-induced PC12 cells. Western blot analysis and quantification of immunoblot for the ratio of Bax and Bcl-2 to $\beta$-actin, respectively. Results are represented as mean $\pm \mathrm{SEM}$ of four independent experiments. ${ }^{* *} P<0.01$ vs. control group; ${ }^{\#} P<0.05$ and ${ }^{\# \#} P<0.01$ vs. CORT group. CORT: corticosterone. 
with a FACS Calibur flow cytometer $(\mathrm{Ex}=488 \mathrm{~nm}$; $\mathrm{Em}=530$ nm) (FCMFC500MPL, Beckman Coulter, Fullerton, CA, USA). PC12 cells $\left(5 \times 10^{5}\right.$ cells per well) were seeded in 6-well plates. After the treatments, the cells were stained with DCFH-DA and observed by inverted fluorescence microscopy (IX71, Olympus, Japan).

\subsection{Mitochondrial membrane potential}

MMP was detected after staining cells with 5,5',6,6'-tetrachloro$1,1^{\prime}, 3,3^{\prime}$-tetraethylbenzimidazolyl-carbo-cyanine iodide (JC-1). PC12 cells $\left(5 \times 10^{5}\right.$ cells per well) were seeded in 6 -well plates. The cells were incubated with $25 \mu \mathrm{M}$ macamides for $1 \mathrm{~h}$, then followed by $25 \mu \mathrm{M}$ macamides plus $400 \mu \mathrm{M}$ CORT treatment. After drug treatment, the cells were harvested, washed with PBS, and then incubated with JC-1 (Beyotime, China, $2 \mathrm{mM}$ for JC-1) at $37^{\circ} \mathrm{C}$ for $30 \mathrm{~min}$ in the dark. After incubation, the cells were washed with PBS and then analyzed with a FACS Calibur flow cytometer $(\mathrm{Ex}=488 \mathrm{~nm}$; $\mathrm{Em}=530 \mathrm{~nm})$.

\subsection{Quantitative real-time PCR}

PC12 cells $\left(5 \times 10^{5}\right.$ cells per well $)$ were seeded in 6 -well plates. The cells were treated with various concentrations of macamides with CORT. After drug treatment, total RNA was extracted from PC12 cells using an RNA extraction kit (Servicebio, China). Total RNA was then reverse transcribed into cDNA using RevertAid First Strand cDNA Synthesis kit (Thermo, USA). Briefly, total RNA was incubated with oligo(dT)18 for $5 \mathrm{~min}$ at $65^{\circ} \mathrm{C}$, and then mixed with a $5 \times$ reaction buffer, dNTP Mix, RiboLock RNAse inhibitor, and RevertAid M-MuLV reverse transcriptase for $60 \mathrm{~min}$ at $42{ }^{\circ} \mathrm{C}$. The reaction was maintained for $10 \mathrm{~min}$ at $70{ }^{\circ} \mathrm{C}$ to inactivate the reverse transcriptase. Quantitative real-time PCR was performed using the StepOne Plus Real-Time PCR System (ABI, USA) and FastStart Universal SYBR Green Master (Rox) (Roche, Switzerland). The forward and reverse primers were as follows: $5^{\prime}$-TGAACTGGACAACAACATGGAG- $3^{\prime}$ and $5^{\prime}$-AGCAAAGTAGAAAAGGGCAACC- $3^{\prime}$ for Bax, $5^{\prime}$-TTGTGGCCTTCTTTGAGTTCG-3 $3^{\prime}$ and $5^{\prime}$-GCATCCCAGCCTCCGTTAT- $3^{\prime}$ for Bcl-2, and $5^{\prime}$-CTGGAGAAACCTGCCAAGTATG-3' ${ }^{\prime}$ and $5^{\prime}$-GGTGGAAGAATGGGAGTTGCT$3^{\prime}$ for GAPDH. Gel electrophoresis and melting curves were used to analyze the PCR products and the specificity of amplification. Transcript levels were quantified by the $\Delta \Delta C_{\mathrm{t}}$ value method using GAPDH for normalization.

\subsection{Annexin V and PI double staining}

The apoptosis rate was determined using a flow cytometer. PC12 cells $\left(5 \times 10^{5}\right.$ cells per well) were seeded in 6-well plates. The cells were incubated with various concentrations of $\mathrm{M}$ 18:3 for $1 \mathrm{~h}$, then followed by various concentrations of $\mathrm{M} 18: 3$ plus $400 \mu \mathrm{M}$
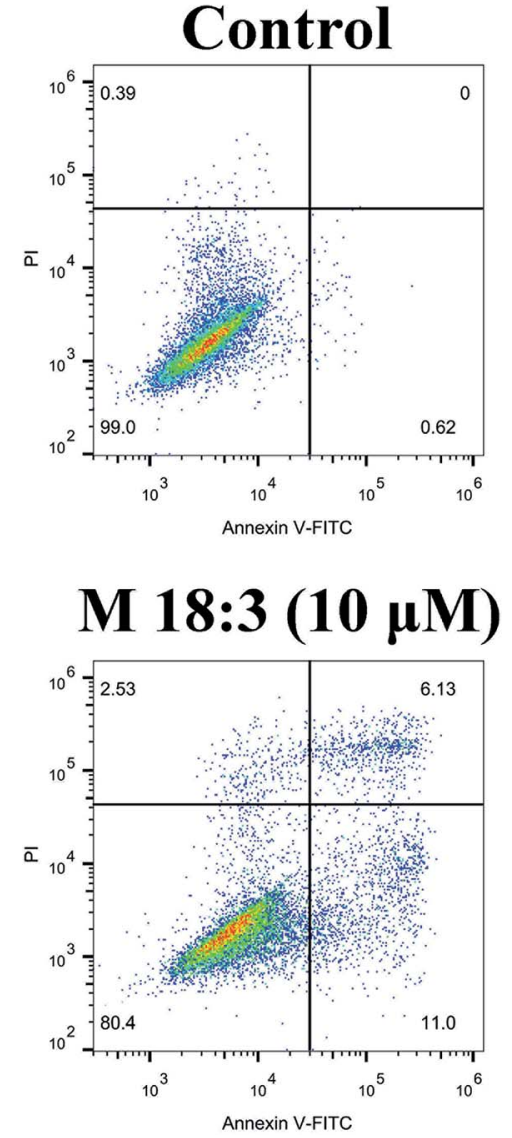

CORT

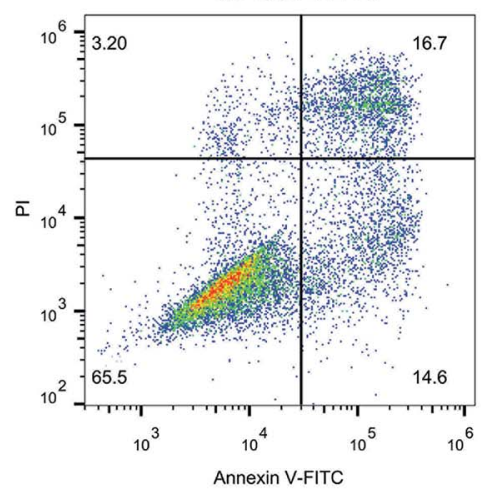

M 18:3 (25 $\mu M)$

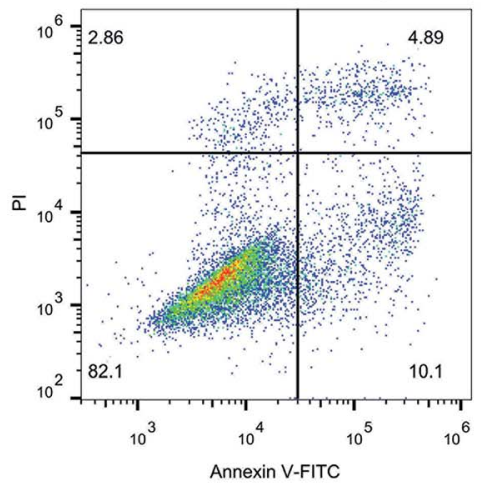

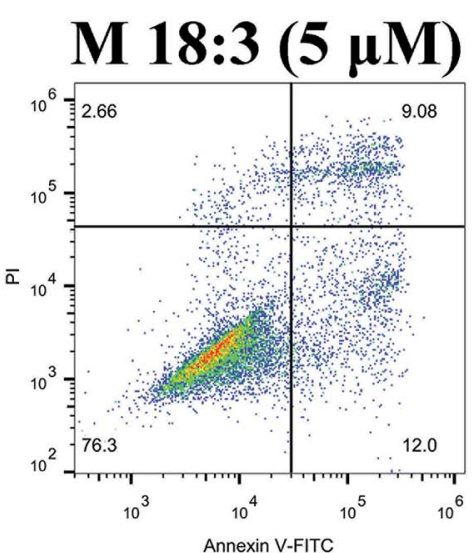

Annexin V-FITC

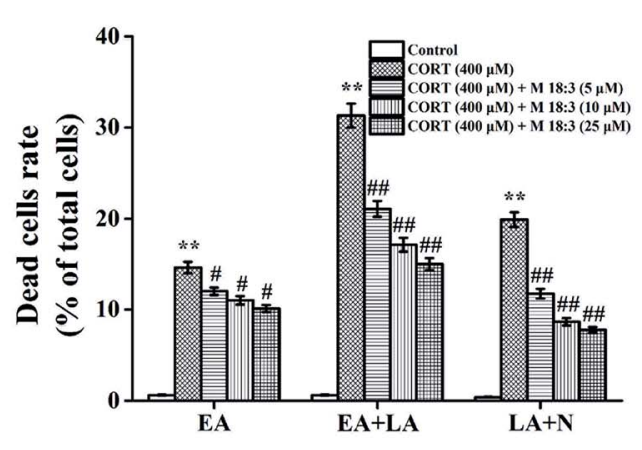

Fig. 5 Protective effect of macamide (M 18:3) $(5 \mu \mathrm{M}, 10 \mu \mathrm{M}, 25 \mu \mathrm{M})$ against apoptosis in CORT-treated PC12 cells. The bar chart describes the perceptual distribution of apoptotic (early apoptosis, EA; late apoptosis, LA; and necrosis, N) cells. Results are represented as mean \pm SEM of four independent experiments. ${ }^{* *} P<0.01$ vs. control group; ${ }^{\#} P<0.05$ and ${ }^{\# \#} P<0.01$ vs. CORT group. CORT: corticosterone. 

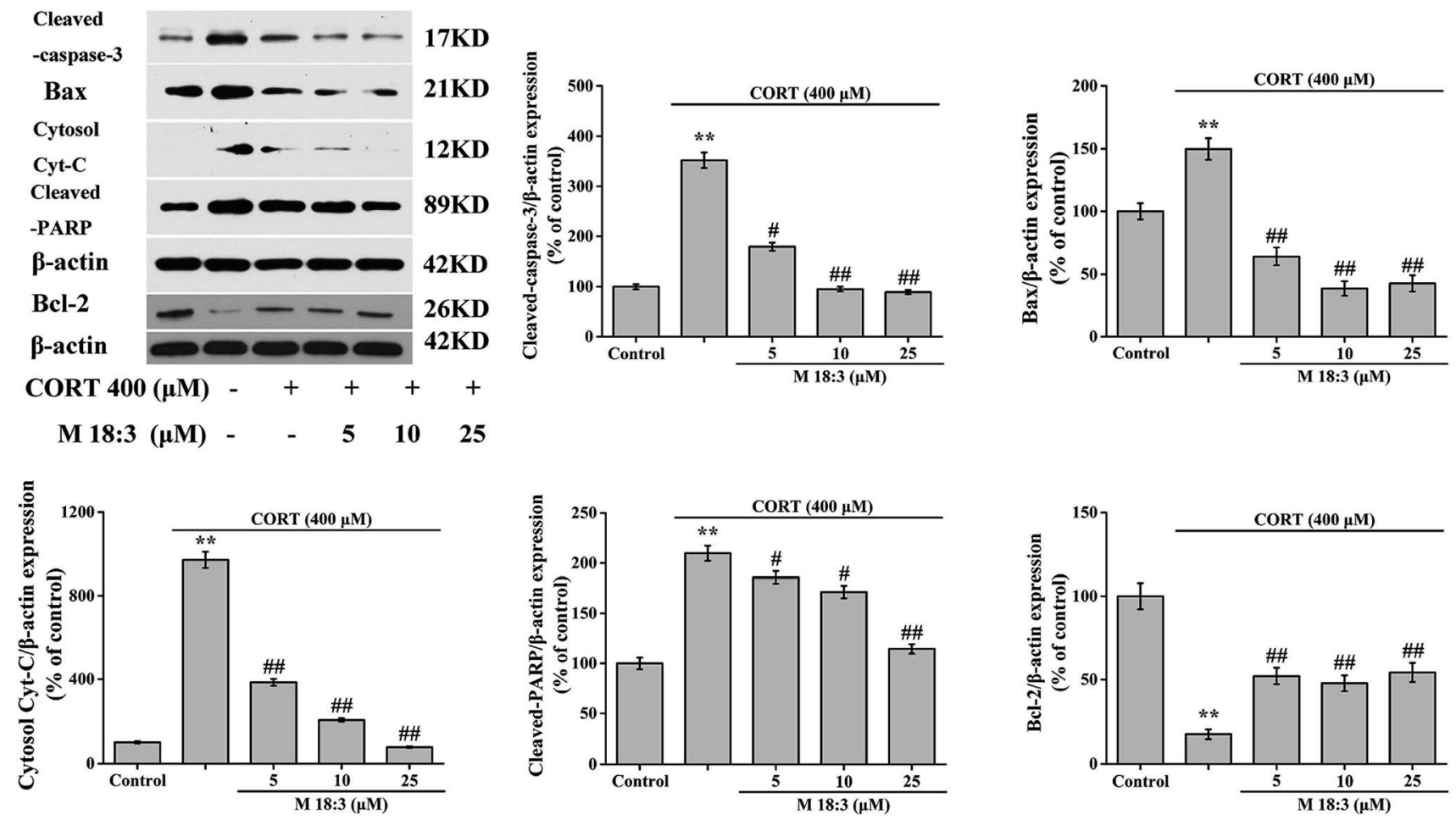

Fig. 6 Protective effect of macamide (M 18:3) $(5 \mu \mathrm{M}, 10 \mu \mathrm{M}, 25 \mu \mathrm{M})$ against apoptosis in CORT-treated PC12 cells. Western blot analysis and quantification of immunoblot for the ratio of cleaved-caspase-3, Bax, cytochrome $C$, cleaved-PPAR and Bcl- 2 to $\beta$-actin, respectively. Results are represented as mean \pm SEM of four independent experiments. ${ }^{* *} P<0.01$ vs. control group; ${ }^{\#} P<0.05$ and ${ }^{\# \#} P<0.01$ vs. CORT group. CORT: corticosterone.

CORT treatment. After drug treatment, the cells were harvested, washed with PBS, and then incubated with the binding buffer containing $5 \mu \mathrm{l}$ annexin V-FITC and $10 \mu \mathrm{l} \mathrm{PI}$ for $15 \mathrm{~min}$ at room temperature in the dark. The suspended cells were analyzed with a FACS Calibur flow cytometer $(\mathrm{Ex}=488 \mathrm{~nm} ; \mathrm{Em}=530 \mathrm{~nm})$.

\subsection{Western blot analysis}

PC12 cells $\left(5 \times 10^{5}\right.$ cells per well) were seeded in 6-well plates. The cells were treated with various concentrations of macamides with CORT. After drug treatment, the PC12 cells were washed thrice with PBS, and homogenized with lysis buffer (Servicebio, China) containing protease and phosphatase inhibitors. The cells were scraped into $1.5 \mathrm{ml}$ centrifuge tubes and incubated on ice for $30 \mathrm{~min}$ to ensure complete cell lysis. After the lysates were centrifuged at $12000 \mathrm{~g}$ for $10 \mathrm{~min}$ at $4{ }^{\circ} \mathrm{C}$, the supernatant was collected for protein and western blot analyses. BCA kit (Servicebio, China) was used to determine the protein concentration. A Nuclear-Cytosol Extraction Kit (Servicebio, Wuhan, China) was used to extract the nuclear and cytoplasmic proteins. Equal amounts of proteins were separated by $10 \%$ SDS-PAGE, transferred onto nitrocellulose membrane (Millipore, USA), and incubated overnight at $4{ }^{\circ} \mathrm{C}$ with primary antibodies against cleaved-caspase-3 (1:500, Rabbit, Cell Signaling), Bax (1:2000, Rabbit, Abcam), cytochrome C (Cyt-C) (1:1000, Rabbit, Servicebio), cleaved-poly (ADP-ribose) polymerase (PARP) (1:500, Rabbit, Cell Signaling), Bcl-2 (1:1000, Rabbit, Abcam), cleaved-caspase-9 (1:1000, Rabbit, Servicebio), p-Akt (1:500, Rabbit, Affinity), Akt (1:500, Rabbit, Affinity), p-CREB (1:1000, Rabbit, Cell Signaling), CREB (1:1000, Rabbit, Cell Signaling), BDNF (1:1000, Rabbit,
Servicebio), $\beta$-actin (1:3000, Mouse, Servicebio), and GAPDH (1:25 000, Mouse, Servicebio). After washing four times for 10 min with TBST, the membranes were incubated with the corresponding secondary antibodies conjugated with HRP (goatanti-rabbit and goat-anti-mouse) at $37^{\circ} \mathrm{C}$ for $1 \mathrm{~h}$. Protein bands were detected using an enhanced chemiluminescence detection kit (Servicebio, China). The blots were quantified using an analytical system (Alpha Innotech, USA), with $\beta$-actin and GAPDH serving as the internal controls for the whole cell lysate and cytosolic fraction proteins.

\subsection{Statistical analysis}

The cell viability, the LDH release rate, and the levels of ROS, mRNA, and protein expression were presented as a percentage of the control. Cell apoptosis rates and MMP levels were expressed as a percentage of the total cells. Data were presented as mean \pm SEM, and all experiments were performed for a minimum of four times. Statistical analysis was performed with SPSS (Version 19.0), and the differences between groups were determined using one-way analysis of variance followed by the least significance difference (LSD) test as appropriate. $P$ Values $<0.01$ and $<0.05$ are indicated in the figures.

\section{Results}

\subsection{Macamides and EEM ameliorated CORT-induced neurotoxicity in PC12 cells}

CORT at $400 \mu \mathrm{M}$ considerably decreased cell viability, which was approximately $50.5 \% \pm 6.2 \%$ and showed concentration 

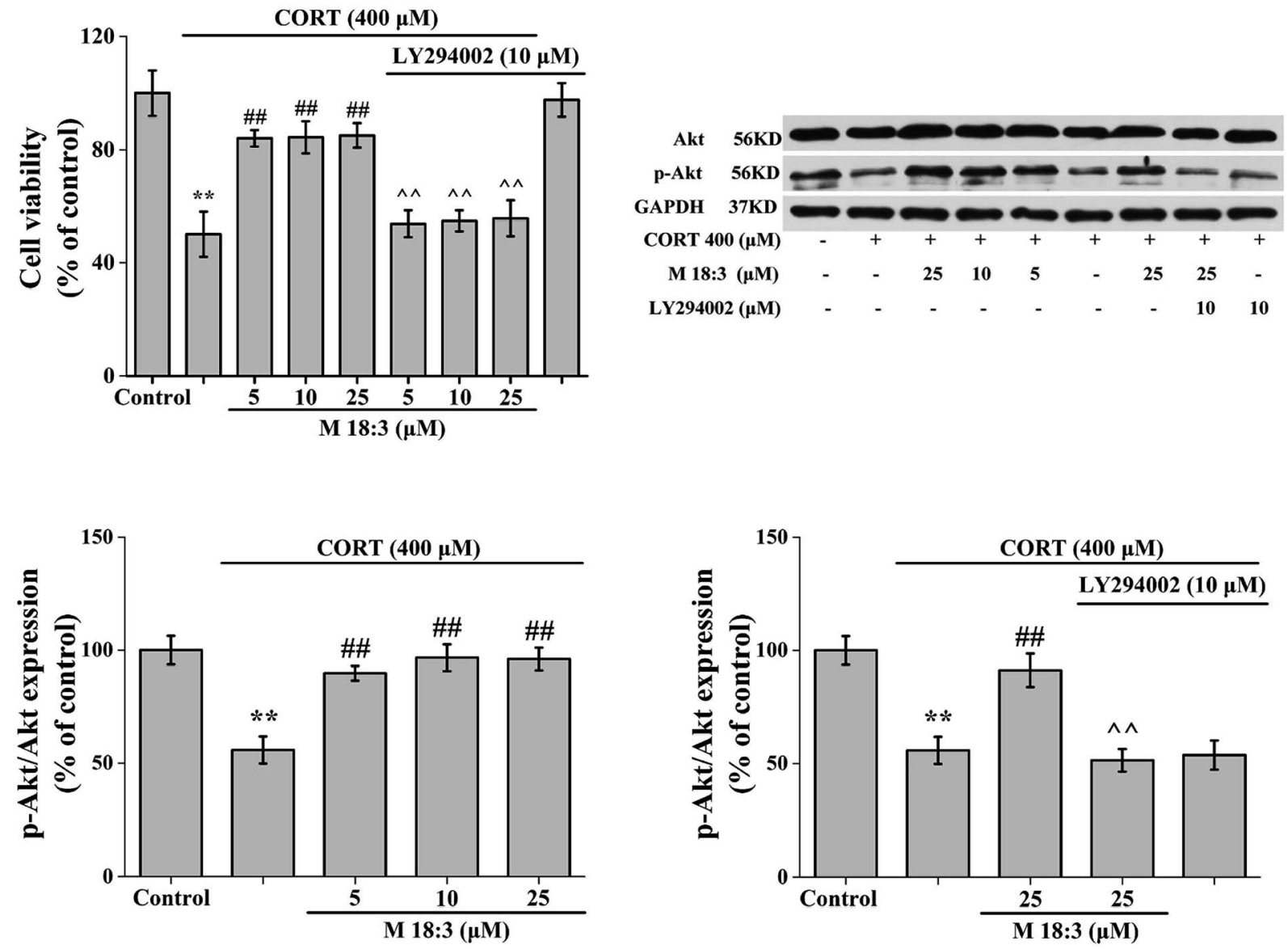

Fig. 7 Macamide (M 18:3) (5 $\mu$ M, $10 \mu \mathrm{M}, 25 \mu \mathrm{M})$ increased Akt phosphorylation in CORT-induced PC12 cells. M 18:3 significantly increased CORTinduced decrease in cell viability, which was blocked by the PI3K/Akt-inhibitor LY294002. Western blot analysis showed that M 18:3 significantly increased the ratio of $p$-Akt/Akt, which was blocked by LY294002. Results are represented as mean \pm SEM of four independent experiments. ** $P$ $<0.01$ vs. control group; ${ }^{\#} P<0.05$ and ${ }^{\# \#} P<0.01$ vs. CORT group; $\wedge \wedge P<0.01$ vs. CORT + M 18:3 group. CORT: corticosterone.

dependence (Fig. S1†). However, EEM at 12.5, 25, and $50 \mu \mathrm{g}$ $\mathrm{ml}^{-1}$ remarkably increased their viability compared with that in the CORT group with the highest being $82.5 \% \pm 6.5 \%$ at $50 \mu \mathrm{g}$ $\mathrm{ml}^{-1}$. Compared with the CORT group, M 18:1, M 18:2, and M $18: 3$ at $5,10,25 \mu \mathrm{M}$ remarkably increased the viability of PC12 cells and the highest was $79.1 \% \pm 2.9 \%, 84.4 \% \pm 5.7 \%$, and $85.1 \% \pm 4.3 \%$ for $\mathrm{M} 18: 3$, respectively. These results suggest that CORT causes damage to PC12 cells, whereas macamides and maca extract improve cell viability in CORT-induced PC12 cells (Fig. 1B).

LDH release is another important indicator of cell injury. CORT at $400 \mu \mathrm{M}$ considerably increased the LDH release, which was about $170.2 \% \pm 7.6 \%$ compared to the control group. However, EEM at 12.5, 25, and $50 \mu \mathrm{g} \mathrm{ml} \mathrm{I}^{-1}$ remarkably decreased the $\mathrm{LDH}$ release and the lowest was $117.8 \% \pm 5.3 \%$ at $50 \mu \mathrm{g}$ $\mathrm{ml}^{-1}$. Compared with the CORT group, M 18:1, M 18:2, and $\mathrm{M}$ $18: 3$ at $5,10,25 \mu \mathrm{M}$ remarkably decreased the LDH release assay, the lowest was $122.1 \% \pm 7.0 \%, 115.5 \% \pm 5.3 \%$, and $113.3 \% \pm 4.8 \%$ for $\mathrm{M} 18: 3$, respectively. These results suggest that CORT increases LDH release whereas macamides and maca extract decrease LDH release in CORT-induced PC12 cells (Fig. 1C).

\subsection{Effects of macamides on intracellular ROS generation in CORT-induced PC12 cells}

Treatment with CORT at $400 \mu \mathrm{M}$ considerably increased the ROS level in PC12 cells to $156.0 \% \pm 8.7 \%$ compared to the control group. Compared with the CORT group, pretreatments with M 18:1, M 18:2, and M 18:3 at $25 \mu \mathrm{M}$ remarkably reduced the ROS levels and the lowest was $98.6 \% \pm 4.4 \%$ for M $18: 3$ (Fig. 2A). Exposure to CORT exhibited a stronger fluorescence intensity than the control group. Pretreatments with M 18:1, M 18:2, and M 18:3 at $25 \mu \mathrm{M}$ reduced the fluorescence intensity, indicating reduced ROS generation (Fig. 2B). Thus, macamides reduced the CORT-induced ROS in PC12 cells.

\subsection{Effects of macamides on MMP and Bax/Bcl-2 ratios in CORT-induced PC12 cells}

CORT at $400 \mu \mathrm{M}$ considerably increased the MMP decline rate in PC12 cells from $15.2 \% \pm 1.4 \%$ to $84.9 \% \pm 6.3 \%$. Compared with the CORT group, pretreatment with $25 \mu \mathrm{M}$ macamides remarkably reduced the MMP decline rates from $84.9 \% \pm 6.3 \%$ to $36.5 \% \pm 2.7 \%$ and $23.4 \% \pm 1.9 \%$ with $\mathrm{M} 18: 2$ and $\mathrm{M} 18: 3$, respectively. $25 \mu \mathrm{M}$ 18:1 did not remarkably decrease the MMP 
decline (Fig. 3A). Thus, $M$ 18:2 and $M$ 18:3 attenuated the reduction of MMP in CORT-treated PC12 cells.

After the cells were treated with $400 \mu \mathrm{M}$ CORT, the Bax/Bcl-2 ratio was increased to $454.9 \% \pm 28.9 \%$. Compared with the

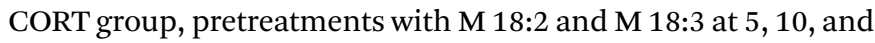
$25 \mu \mathrm{M}$ remarkably decreased the $\mathrm{Bax} / \mathrm{Bcl}-2$ ratios, the lowest were $330.1 \% \pm 21.4 \%, 236.8 \% \pm 14.5 \%$, and $178.1 \% \pm 12.7 \%$ for $M$ 18:3, respectively. In addition, we found that $M$ 18:1 at 5, 10 , and $25 \mu \mathrm{M}$ showed no evident effect on the mRNA levels of Bax and Bcl-2 (Fig. 3B). Thus, M 18:2 and M 18:3 could reduce the Bax/Bcl-2 ratios in CORT-induced PC12 cells.

Treatment with CORT at $400 \mu \mathrm{M}$ considerably increased the expression level of Bax in PC12 cells compared to the control group. Compared with the CORT group, pretreatments with $\mathrm{M}$

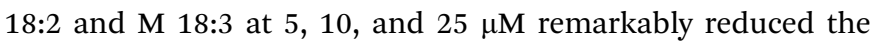
expression levels of Bax. $400 \mu \mathrm{M}$ CORT considerably reduced the expression level of Bcl-2. However, pretreatments of PC12 cells with $M$ 18:2 and $M$ 18:3 at 5, 10, and $25 \mu \mathrm{M}$ remarkably increased the expression levels of Bcl-2. M 18:1 at 5, 10, and 25 $\mu \mathrm{M}$ showed no evident effect on the expression levels of Bax and Bcl-2 (Fig. 4). Thus, M 18:2 and M 18:3 could reduce the Bax expressions and increase the Bcl-2 expressions in CORTinduced PC12 cells.

3.4. Effects of macamide (M 18:3) on apoptosis and the expressions of pro-apoptotic proteins in CORT-induced PC12 cells

Treatment with $400 \mu \mathrm{M}$ CORT increased the percentages of early apoptotic (EA) cells, EA cells + late apoptotic (LA) cells, and LA cells + necrotic cells to $14.6 \% \pm 0.6 \%, 31.3 \% \pm 1.3 \%$, and
$19.9 \% \pm 0.8 \%$, respectively. Pretreatment with M 18:3 at 5, 10, and $25 \mu \mathrm{M}$ remarkably reduced the percentages of these cells and the lowest were $10.1 \% \pm 0.4 \%, 15.0 \% \pm 0.7 \%$, and $7.8 \% \pm$ $0.3 \%$ at $25 \mu \mathrm{M}$, respectively (Fig. 5). Thus, macamides inhibited CORT-induced apoptosis in PC12 cells. CORT treatment considerably increased the expression levels of cleaved-caspase3, Bax, cytochrome $\mathrm{C}$, and cleaved-PARP and remarkably decreased the expression level of Bcl-2. However, pretreatment

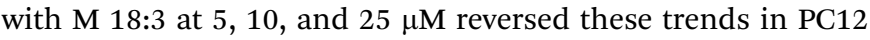
cells (Fig. 6). Thus, M 18:3 could inhibit apoptosis, reduce the expression of pro-apoptotic proteins and increase $\mathrm{Bcl}-2$ expression in CORT-induced PC12 cells.

3.5. Effects of macamide (M 18:3) on the expression levels of pro-survival proteins (Akt, CREB and BDNF) in CORT-induced PC12 cells

Treatment of PC12 cells with $10 \mu \mathrm{M}$ LY294002 for $24 \mathrm{~h}$ had no effect on the viability of normal cells. When PC12 cells were treated with $400 \mu \mathrm{M}$ CORT for $24 \mathrm{~h}$, cell viability was decreased significantly. However, after PC12 cells were pretreated with M 18:3 for $1 \mathrm{~h}$ and then incubated with CORT for $24 \mathrm{~h}$, cell viability was significantly increased. Interestingly, when PC12 cells were pretreated with $10 \mu \mathrm{M}$ LY294002 for $1 \mathrm{~h}$ followed by incubation

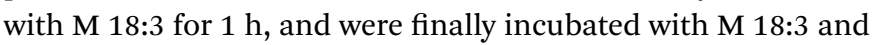
CORT for $24 \mathrm{~h}$, cell viability was significantly reduced (Fig. 7).

The expression level of Akt was slightly increased by $25 \mu \mathrm{M} \mathrm{M}$ 18:3, but not remarkably, whereas $400 \mu \mathrm{M}$ CORT considerably reduced the expression level of p-Akt. However, pretreatment of PC12 cells with M 18:3 remarkably increased the expression
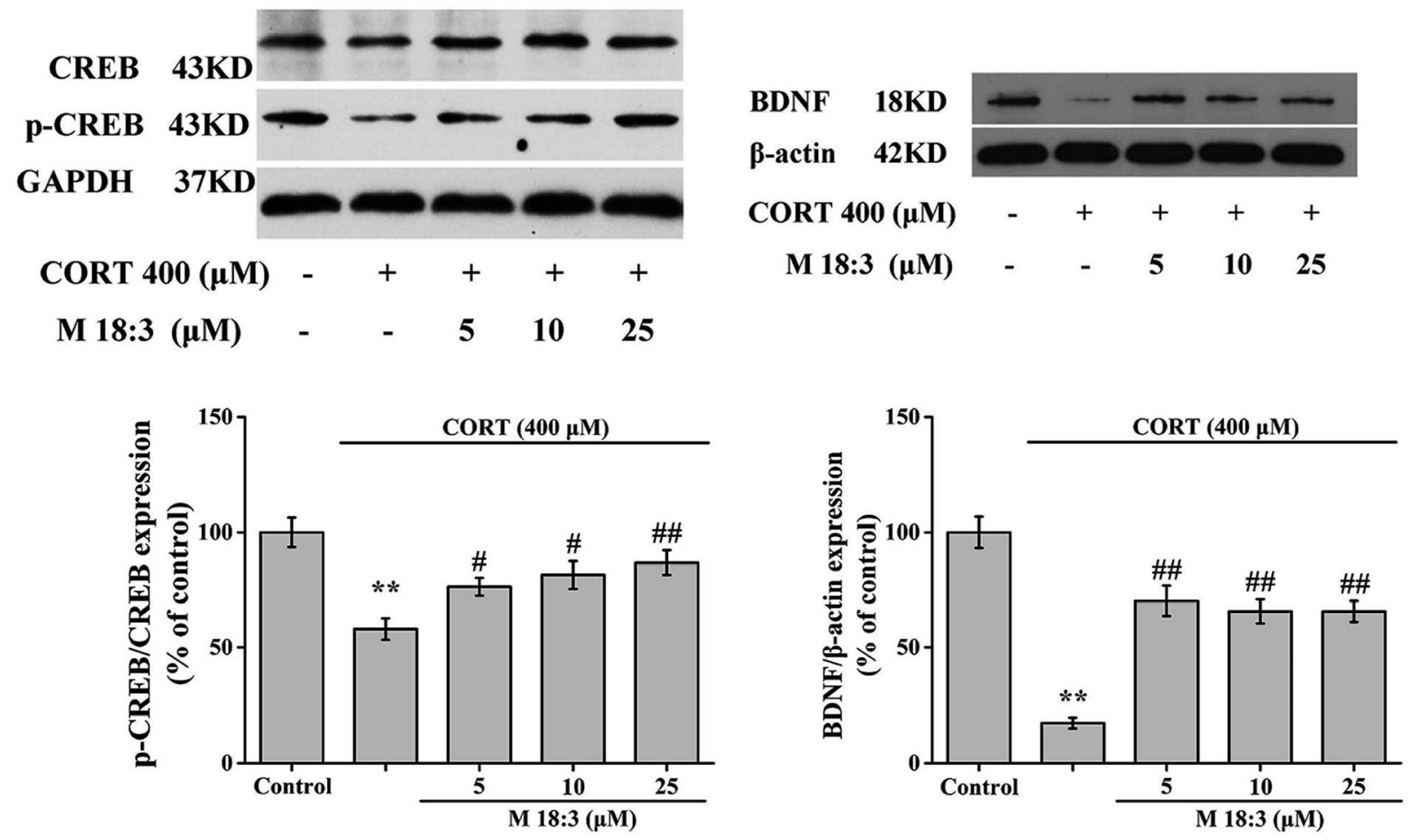

Fig. 8 Macamide (M 18:3) $(5 \mu M, 10 \mu M, 25 \mu M)$ increased the expression levels of $p$-CREB/CREB and BDNF in CORT-induced PC12 cells. Results are represented as mean \pm SEM of four independent experiments. ${ }^{* *} P<0.01 \mathrm{vs}$. control group; ${ }^{\#} P<0.05$ and ${ }^{\# \#} P<0.01$ vs. CORT group. CORT: corticosterone. 
level of p-Akt. Interestingly, when PC12 cells were pretreated with LY294002, the above trend was reversed. At the same time, there was no significant change in p-Akt levels in the inhibitor LY294002 plus CORT group compared with that in the CORT group, indicating that the inhibitor LY294002 could not cause interference with the system (Fig. 7).

CORT at $400 \mu \mathrm{M}$ considerably decreased the expression levels of p-CREB/CREB and BDNF. However, pretreatment with $\mathrm{M} \mathrm{18:3}$ at 5, 10, and $25 \mu \mathrm{M}$ remarkably increased the expression levels of $\mathrm{p}$-CREB/CREB and BDNF (Fig. 8). In summary, the above results showed that treatment with CORT reduced the expression levels of p-Akt, p-CREB, and BDNF whereas pretreatment with M 18:3 increased these.

\section{Discussion and conclusions}

This study demonstrated that CORT treatment decreased cell viability and increased LDH release. However, EEM and macamides increased the cell viability and decreased $\mathrm{LDH}$ release, among which $\mathrm{M}$ 18:3 was superior to EEM. These results showed that EEM and macamides exert protective effects against CORT-induced cytotoxicity, and that macamides may be potential neuroprotectants in EEM. Gugnani et al. investigated the neurotoxicity of $\mathrm{Mn}$ and found that macamides can counter this toxicity by binding to the CB1 receptor. ${ }^{32} \mathrm{Mn}$ is an environmental toxin that could cause Parkinson's disease. However, we used CORT, a hormone secreted by mammals, to damage PC12 cells as excessive CORT can cause nervous system disorders related to chronic stress. ${ }^{1}$

Long-term exposure to high levels of glucocorticoids increases intracellular ROS. ${ }^{\mathbf{5 1 , 5 2}}$ Excessive ROS levels in cells can disrupt redox balance, damage biomacromolecules, and activate Bax to cause apoptosis. ${ }^{53}$ M 18:2 and M 18:3 reduced the intracellular ROS generation, inhibited MMP decline rates, and reduced the $\mathrm{Bax} / \mathrm{Bcl}-2$ ratios. These results suggest that $\mathrm{M}$ 18:2 and M 18:3 might protect PC12 cells from CORT-induced mitochondrial injury by reducing oxidative stress at least in part. M 18:1 increased the cell viability and reduced intracellular ROS without producing other beneficial effects. These results showed that $M$ 18:1 possessed weaker anti-apoptosis activity compared to $M$ 18:2 and $M$ 18:3 against CORTinduced cytotoxicity in PC12 cells. In this study, all three macamides exhibited protective effects against CORT-induced cell damage. However, M 18:2 and M 18:3 exhibited better protective effects. It is speculated that with an increase in the number of double bonds, the ability of macamide to scavenge ROS was enhanced and the ability to inhibit the damage produced by CORT was also enhanced. Similar experimental results were obtained with oleic acid, which with one double bond is structurally similar to $\mathrm{M} 18: 1$, and with alpha-linolenic acid (ALA), which with three double bonds is structurally similar to $M$ 18:3. These fatty acids protect neurons by lowering ROS levels, which may be result from the scavenge of free radicals through their double bonds, rather than by increasing the activity of antioxidant enzymes. ${ }^{\mathbf{5 4 , 5 5}}$

The Bcl-2 family proteins exists on the membranes of cells as well as the nuclear, mitochondrial, and endoplasmic reticulum membranes. There are several subtypes including the proapoptotic protein Bax, pro-apoptotic protein Bid, and antiapoptotic protein Bcl-2. ${ }^{56}$ Bax is involved in the formation of mitochondrial permeability transporter pores (MPTPs). When MPTPs are opened, mitochondrial depolarization and MMP decrease are observed, and various cytokines in mitochondria such as Cyt-C, Smac, AIF, and EndoG, are released to the cytoplasm to induce caspase and mitochondrial dependent apoptosis. ${ }^{57,58} \mathrm{Bcl}-2$ can competitively bind to Bax on the mitochondrial membrane to form a Bcl-2/Bax heterodimer resulting in closing of the MPTPs and preventing the release of proapoptotic factors from mitochondria, thus achieving an antiapoptotic effect. ${ }^{53}$ High levels of CORT cause nerve cell apoptosis in vitro and vivo..$^{6,7,12,59}$ Zhou et al. suggested a potential mechanism of toxicity by CORT: CORT causes a large increase in the levels of intracellular ROS, decreases MMP, releases cytochrome $\mathrm{C}$, activates caspase-3, and all of this inducing apoptosis. ${ }^{53}$ In our experiment, CORT remarkably increased the number of early and late apoptotic cells, whereas the number of apoptotic cells was considerably reduced after $\mathbf{M}$ 18:3 treatment. Moreover, CORT increased the expression levels of cleaved-caspase-3, Bax, cytochrome C, and cleaved-PARP, and decreased the expression level of Bcl-2. However, M 18:3 reduced the $\mathrm{Bax} / \mathrm{Bcl}-2$ ratio and the expression levels of Bax, cytochrome C, cleaved-caspase-3, and cleaved-PARP. These results suggested that $M$ 18:3 could inhibit mitochondrial apoptosis and regulate the pro-apoptotic proteins.

The PI3K/Akt signaling pathway is one of the most important pathways involved in regulating cell proliferation. ${ }^{60}$ Activation of the PI3K/Akt pathway prevents apoptosis. PI3K enhances neuroprotective effects through phosphorylation of Akt, which is a pro-survival kinase. Through the PI3K pathway, Akt is phosphorylated at the Ser473 site, playing a key role in the survival of neurons. Phosphorylated Akt affects the downstream apoptosis-related proteins such as Bcl-2 family proteins, GSK$3 \beta$, and caspase- 3 , and plays a protective role against apoptosis. ${ }^{61,62}$ In this study, CORT considerably reduced the

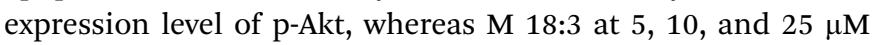
increased the expression levels of p-Akt. When the PC12 cells were pretreated with the PI3K/Akt inhibitor LY294002, the ability of M 18:3 to induce phosphorylation of Akt was inhibited. Moreover, when LY294002 was added, the ability of M 18:3 to protect against CORT-induced cytotoxicity was remarkably reduced. These results suggest that $M$ 18:3 could promote the phosphorylation of Akt in CORT-induced PC12 cells. Similar experimental results are also reported previously. ALA, which is structurally similar to M 18:3, promotes Akt phosphorylation in high glucose-induced cultured HUVECs. ${ }^{63}$ Long-term dietary intake of ALA activates Akt signaling in the hippocampus of natural aging rats. ${ }^{64}$

CREB is a transcription factor involved in critical functions such as neuronal plasticity and survival. CREB is phosphorylated at Ser133, and p-CREB is its active form. Activated CREB can improve cell survival by regulating BDNF expression, ${ }^{\mathbf{6 5 , 6 6}}$ which is considered an important factor for neuronal survival. ${ }^{35}$ In this study, M 18:3 increased the expression levels of p-CREB and BDNF. This result suggested that M 18:3 might improve the 
phosphorylation of CREB, and then activate the BDNF protein synthesis thereby attenuating CORT-induced neurotoxicity.

In conclusion, macamides, especially $M$ 18:3, could inhibit CORT-induced neurotoxicity in PC12 cells. The cellular mechanism of M 18:3 against CORT-induced cytotoxicity may involve decrease in intracellular ROS, inhibition of mitochondrial apoptosis, and activation of Akt and CREB phosphorylation. Overall, macamides may potentially treat neuronal damage induced by CORT.

\section{Conflicts of interest}

No conflicts of interest are declared for any of the authors.

\section{Abbreviations}

$\begin{array}{ll}\text { LDH } & \text { Lactate dehydrogenase } \\ \text { ROS } & \text { Reactive oxygen species } \\ \text { MMP } & \text { Mitochondrial membrane potential } \\ \text { FBS } & \text { Fetal bovine serum } \\ \text { HS } & \text { Horse serum } \\ \text { DMEM } & \text { Dulbecco's modified Eagle medium } \\ \text { PI3K/Akt } & \text { Phosphoinositide 3-kinase/protein kinase B } \\ \text { CREB } & \text { cAMP-response element binding protein } \\ \text { BDNF } & \text { Brain-derived neurotrophic factor } \\ \text { HUVECs } & \text { Human umbilical vein endothelial cells }\end{array}$

\section{Acknowledgements}

This research work was supported by National Natural Science Foundation of China (Grant No. J1103514), Nature Science Foundation of Hubei Province (No. 2012FFB02607). The authors thank the Analytical and Testing Center of Huazhong University of Science and Technology for the LC-MS analysis of macamides.

\section{References}

1 Y. Noh, S. Cheon, I. H. Kim, I. Kim, S. A. Lee, D. H. Kim and Y. Jeong, The protective effects of ethanolic extract of Clematis terniflora against corticosterone-induced neuronal damage via the AKT and ERK1/2 pathway, BMB Rep., 2018, 51, 400-405.

2 M. Aihara, I. Ida, N. Yuuki, A. Oshima, H. Kumano, K. Takahashi, M. Fukuda, N. Oriuchi, K. Endo, H. Matsuda and M. Mikuni, HPA axis dysfunction in unmedicated major depressive disorder and its normalization by pharmacotherapy correlates with alteration of neural activity in prefrontal cortex and limbic/paralimbic regions, Psychiatry Res., Neuroimaging, 2007, 155, 245-256.

3 F. Murray, D. W. Smith and P. H. Hutson, Chronic low dose corticosterone exposure decreased hippocampal cell proliferation, volume and induced anxiety and depression like behaviours in mice, Eur. J. Pharmacol., 2008, 583, 115127.
4 M. Y. Zhu, W. P. Wang and G. Bissette, Neuroprotective effects of agmatine against cell damage caused by glucocorticoids in cultured rat hippocampal neurons, Neuroscience, 2006, 141, 2019-2027.

5 H. Chen, G. N. Pandey and Y. Dwivedi, Hippocampal cell proliferation regulation by repeated stress and antidepressants, NeuroReport, 2006, 17, 863-867.

$6 \mathrm{M}$. Gao, H. Zhou and X. Li, Curcumin protects PC12 cells from corticosterone-induced cytotoxicity: possible involvement of the ERK1/2 pathway, Basic Clin. Pharmacol. Toxicol., 2009, 104, 236-240.

7 M. Zheng, C. Liu, F. Pan, D. Shi, F. Ma, Y. Zhang and Y. Zhang, Protective effects of flavonoid extract from Apocynum venetum leaves against corticosterone-induced neurotoxicity in PC12 cells, Cell. Mol. Neurobiol., 2011, 31, 421-428.

8 B. P. Jiang, Y. M. Liu, L. Le, Z. Y. Li, J. Y. Si, X. M. Liu, Q. Chang and R. L. Pan, Cajaninstilbene acid prevents corticosterone-induced apoptosis in PC12 cells by inhibiting the mitochondrial apoptotic pathway, Cell. Physiol. Biochem., 2014, 34, 1015-1026.

9 Y. Liu, S. Shen, Z. Li, Y. Jiang, J. Si, Q. Chang, X. Liu and R. Pan, Cajaninstilbene acid protects corticosteroneinduced injury in PC12 cells by inhibiting oxidative and endoplasmic reticulum stress-mediated apoptosis, Neurochem. Int., 2014, 78, 43-52.

10 F. Wu, H. Li, L. Zhao, X. Li, J. You, Q. Jiang, S. Li, L. Jin and $\mathrm{Y}$. $\mathrm{Xu}$, Protective effects of aqueous extract from Acanthopanax senticosus against corticosterone-induced neurotoxicity in PC12 cells, J. Ethnopharmacol., 2013, 148, 861-868.

11 A. Nitta, W. H. Zheng and R. Quirion, Insulin-like growth factor 1 prevents neuronal cell death induced by corticosterone through activation of the PI3k/Akt pathway, J. Neurosci. Res., 2004, 76, 98-103.

12 Z. Y. Li, Z. Guo, Y. M. Liu, X. M. Liu, Q. Chang, Y. H. Liao and R. L. Pan, Neuroprotective effects of Total Saikosaponins of Bupleurum yinchowense on corticosterone-induced apoptosis in PC12 cells, J. Ethnopharmacol., 2013, 148, 794803.

13 H. E. Flores, T. S. Walker, R. L. Guimarães, H. P. Bais and J. M. Vivanco, Andean root and tuber crops: Underground rainbows, HortScience, 2003, 38, 161-167.

14 Y. Wang, Y. Wang, B. McNeil and L. M. Harvey, Maca: An Andean crop with multi-pharmacological functions, Food Res. Int., 2007, 40, 783-792.

15 G. F. Gonzales, Ethnobiology and Ethnopharmacology of Lepidium meyenii (Maca), a Plant from the Peruvian Highlands, J. Evidence-Based Complementary Altern. Med., 2012, 2012, 193496.

16 S. Zha, Q. Zhao, J. Chen, L. Wang, G. Zhang, H. Zhang and B. Zhao, Extraction, purification and antioxidant activities of the polysaccharides from maca (Lepidium meyenii), Carbohydr. Polym., 2014, 111, 584-587.

17 E. H. Choi, J. I. Kang, J. Y. Cho, S. H. Lee, T. S. Kim, I. H. Yeo and H. S. Chun, Supplementation of standardized lipidsoluble extract from maca (Lepidium meyenii) increases 
swimming endurance capacity in rats, J. Funct. Foods, 2012, 4, 568-573.

18 Y. Zhang, L. Yu, M. Ao and W. Jin, Effect of ethanol extract of Lepidium meyenii Walp. on osteoporosis in ovariectomized rat, J. Ethnopharmacol., 2006, 105, 274-279.

19 C. Gonzales, J. Rubio, M. Gasco, J. Nieto, S. Yucra and G. F. Gonzales, Effect of short-term and long-term treatments with three ecotypes of Lepidium meyenii (MACA) on spermatogenesis in rats, J. Ethnopharmacol., 2006, 103, 448-454.

20 M. S. Lee, B. C. Shin, E. J. Yang, H. J. Lim and E. Ernst, Maca (Lepidium meyenii) for treatment of menopausal symptoms: a systematic review, Maturitas, 2011, 70, 227-233.

21 Z. Ai, A. F. Cheng, Y. T. Yu, L. J. Yu and W. Jin, Antidepressant-like behavioral, anatomical, and biochemical effects of petroleum ether extract from maca (Lepidium meyenii) in mice exposed to chronic unpredictable mild stress, J. Med. Food, 2014, 17, 535-542.

22 J. Rubio, M. Caldas, S. Dávila, M. Gasco and G. F. Gonzales, Effect of three different cultivars of Lepidium meyenii (Maca) on learning and depression in ovariectomized mice, $B M C$ Complementary Altern. Med., 2006, 6, 23.

23 L. Stojanovska, C. Law, B. Lai, T. Chung, K. Nelson, S. Day, V. Apostolopoulos and C. Haines, Maca reduces blood pressure and depression, in a pilot study in postmenopausal women, Climacteric, 2015, 18, 69-78.

24 S. S. Guo, X. F. Gao, Y. R. Gu, Z. X. Wan, A. M. Lu, Z. H. Qin and L. Luo, Preservation of Cognitive Function by Lepidium meyenii (Maca) Is Associated with Improvement of Mitochondrial Activity and Upregulation of AutophagyRelated Proteins in Middle-Aged Mouse Cortex, J. EvidenceBased Complementary Altern. Med., 2016, 2016, 4394261.

25 J. Rubio, H. Dang, M. Gong, X. Liu, S. L. Chen and G. F. Gonzales, Aqueous and hydroalcoholic extracts of Black Maca (Lepidium meyenii) improve scopolamineinduced memory impairment in mice, Food Chem. Toxicol., 2007, 45, 1882-1890.

26 J. Rubio, S. Yucra, M. Gasco and G. F. Gonzales, Doseresponse effect of black maca (Lepidium meyenii) in mice with memory impairment induced by ethanol, Toxicol. Mech. Methods, 2011, 21, 628-634.

27 J. Rubio, W. Qiong, X. Liu, Z. Jiang, H. Dang, S. L. Chen and G. F. Gonzales, Aqueous extract of black maca (Lepidium meyenii) on memory impairment induced by ovariectomy in mice, J. Evidence-Based Complementary Altern. Med., 2008, 2011, 253958.

28 A. Pino-Figueroa, D. Nguyen and T. J. Maher, Neuroprotective effects of Lepidium meyenii (Maca), Ann. N. Y. Acad. Sci., 2010, 1199, 77-85.

29 A. Pino-Figueroa, H. Vu, C. J. Kelley and T. J. Maher, Mechanism of Action of Lepidium meyenii (Maca): An Explanation for Its Neuroprotective Activity, Am. J. Neuroprot. Neuroregener., 2011, 3, 87-92.

30 M. M. Mccollom, J. R. Villinski, K. L. Mcphail, L. E. Craker and S. Gafner, Analysis of macamides in samples of Maca (Lepidium meyenii) by HPLC-UV-MS/MS, Phytochem. Anal., 2005, 16, 463-469.
31 J. Zhao, I. Muhammad, D. C. Dunbar, J. Mustafa and I. A. Khan, New alkamides from maca (Lepidium meyenii), J. Agric. Food Chem., 2005, 53, 690-693.

32 K. S. Gugnani, N. Vu, A. N. Rondón-Ortiz, M. Böhlke, T. J. Maher and A. J. Pino-Figueroa, Neuroprotective activity of macamides on manganese-induced mitochondrial disruption in U-87 MG glioblastoma cells, Toxicol. Appl. Pharmacol., 2018, 340, 67-76.

33 Q. Yang, W. Jin, X. Lv, P. Dai, Y. Ao, M. Wu, W. Deng and L. Yu, Effects of macamides on endurance capacity and anti-fatigue property in prolonged swimming mice, Pharm. Biol., 2016, 54, 827-834.

34 H. Liu, W. Jin, C. Fu, P. Dai, Y. Yu, Q. Huo and L. Yu, Discovering anti-osteoporosis constituents of maca (Lepidium meyenii) by combined virtual screening and activity verification, Food Res. Int., 2015, 77, 215-220.

35 Y. Zhou, P. Li, A. Brantner, H. Wang, X. Shu, J. Yang, N. Si, L. Han, H. Zhao and B. Bian, Chemical profiling analysis of Maca using UHPLC-ESI-Orbitrap MS coupled with UHPLC-ESI-QqQ MS and the neuroprotective study on its active ingredients, Sci. Rep., 2017, 7, 44660.

36 X. Yan, T. Chen, L. Zhang and H. Du, Protective effects of Forsythoside A on amyloid beta-induced apoptosis in PC12 cells by downregulating acetylcholinesterase, Eur. J. Pharmacol., 2017, 810, 141-148.

37 Z. Hajdu, S. Nicolussi, M. Rau, L. Lorántfy, P. Forgo, J. Hohmann, D. Csupor and J. Gertsch, Identification of endocannabinoid system-modulating $\mathrm{N}$-alkylamides from Heliopsis helianthoides var. scabra and Lepidium meyenii, J. Nat. Prod., 2014, 77, 1663-1669.

$38 \mathrm{H}$. Wu, C. J. Kelley, A. Pino-Figueroa, H. D. Vu and T. J. Maher, Macamides and their synthetic analogs: evaluation of in vitro FAAH inhibition, Bioorg. Med. Chem., 2013, 21, 5188-5197.

39 H. Almukadi, H. Wu, M. Böhlke, C. J. Kelley, T. J. Maher and A. Pino-Figueroa, The macamide $N$-3-methoxybenzyllinoleamide is a time-dependent fatty acid amide hydrolase (FAAH) inhibitor, Mol. Neurobiol., 2013, 48, 333339.

40 J. Hwang, C. Adamson, D. Butler, D. R. Janero, A. Makriyannis and B. A. Bahr, Enhancement of endocannabinoid signaling by fatty acid amide hydrolase inhibition: a neuroprotective therapeutic modality, Life Sci., 2010, 86, 615-623.

41 D. Piomelli, G. Tarzia, A. Duranti, A. Tontini, M. Mor, T. R. Compton, O. Dasse, E. P. Monaghan, J. A. Parrott and D. Putman, Pharmacological profile of the selective FAAH inhibitor KDS-4103 (URB597), CNS Drug Rev., 2006, 12, 2138.

42 S. H. Su, Y. Q. Wang, Y. F. Wu, D. P. Wang, Q. Lin and J. Hai, Cannabinoid receptor agonist win55,212-2 and fatty acid amide hydrolase inhibitor URB597 may protect against cognitive impairment in rats of chronic cerebral hypoperfusion via PI3K/AKT signaling, Behav. Brain Res., 2016, 313, 334-344.

43 S. H. Su, Y. F. Wu, Q. Lin, F. Yu and J. Hai, Cannabinoid receptor agonist win55,212-2 and fatty acid amide 
hydrolase inhibitor URB597 suppress chronic cerebral hypoperfusion-induced neuronal apoptosis by inhibiting cJun N-terminal kinase signaling, Neuroscience, 2015, 301, 563-575.

44 L. R. Vilela, P. H. Gobira, T. G. Viana, D. C. Medeiros, T. H. Ferreira-Vieira, J. G. Doria, F. Rodrigues, D. C. Aguiar, G. S. Pereira, A. R. Massessini, F. M. Ribeiro, A. C. P. de Oliveira, M. F. D. Moraes and F. A. Moreira, Enhancement of endocannabinoid signaling protects against cocaine-induced neurotoxicity, Toxicol. Appl. Pharmacol., 2015, 286, 178-187.

45 B. Zeng, Y. Li, B. Niu, X. Wang, Y. Cheng, Z. Zhou, T. You, Y. Liu, H. Wang and J. Xu, Involvement of PI3K/Akt/ FoxO3a and PKA/CREB Signaling Pathways in the Protective Effect of Fluoxetine Against CorticosteroneInduced Cytotoxicity in PC12 Cells, J. Mol. Neurosci., 2016, 59, 567-578.

46 Z. Zeng, X. Wang, S. K. Bhardwaj, X. Zhou, P. J. Little, R. Quirion, L. K. Srivastava and W. Zheng, The Atypical Antipsychotic Agent, Clozapine, Protects Against Corticosterone-Induced Death of PC12 Cells by Regulating the Akt/FoxO3a Signaling Pathway, Mol. Neurobiol., 2017, 54, 3395-3406.

47 H. A. Elgebaly, N. M. Mosa, M. Allach, K. F. El-Massry, A. H. El-Ghorab, A. M. Al Hroob and A. M. Mahmoud, Olive oil and leaf extract prevent fluoxetine-induced hepatotoxicity by attenuating oxidative stress, inflammation and apoptosis, Biomed. Pharmacother., 2018, 98, 446-453.

48 I. Reznik, L. Volchek, R. Mester, M. Kotler, I. Sarova-Pinhas, B. Spivak and A. Weizman, Myotoxicity and Neurotoxicity during Clozapine Treatment, Clin. Neuropharmacol., 2000, 23, 276-280.

49 A. Goto, A. Mouri, T. Nagai, A. Yoshimi, M. Ukigai, T. Tsubai, H. Hida, N. Ozaki and Y. Noda, Involvement of the histamine $\mathrm{H}_{4}$ receptor in clozapine-induced hematopoietic toxicity: Vulnerability under granulocytic differentiation of HL-60 cells, Toxicol. Appl. Pharmacol., 2016, 306, 8-16.

50 Y. Jiang, Z. Li, Y. Liu, X. Liu, Q. Chang, Y. Liao and R. Pan, Neuroprotective effect of water extract of Panax ginseng on corticosterone-induced apoptosis in PC12 cells and its underlying molecule mechanisms, J. Ethnopharmacol., 2015, 159, 102-112.

51 L. J. McIntosh and R. M. Sapolsky, Glucocorticoids Increase the Accumulation of Reactive Oxygen Species and Enhance Adriamycin-Induced Toxicity in Neuronal Culture, Exp. Neurol., 1996, 141, 201-206.

52 R. M. Sapolsky, D. R. Packan and W. W. Vale, Glucocorticoid toxicity in the hippocampus: in vitro demonstration, Brain Res., 1988, 453, 367-371.

53 Y. Z. Zhou, X. Li, W. X. Gong, J. S. Tian, X. X. Gao, L. Gao, X. Zhang, G. H. Du and X. M. Qin, Protective effect of isoliquiritin against corticosterone-induced neurotoxicity in PC12 cells, Food Funct., 2017, 8, 1235-1244.

54 H. Kim, K. Youn, E. Y. Yun, J. S. Hwang, W. S. Jeong, C. T. Ho and $\mathrm{M}$. Jun, Oleic acid ameliorates A $\beta$-induced inflammation by downregulation of COX-2 and iNOS via NFкB signaling pathway, J. Funct. Foods, 2015, 14, 1-11.

55 A. Y. Lee, M. H. Lee, S. Lee and E. J. Cho, Neuroprotective effect of alpha-linolenic acid against $\mathrm{A} \beta$-mediated inflammatory responses in C6 glial cell, J. Agric. Food Chem., 2018, 66, 4853-4861.

56 T. A. Kosten, M. P. Galloway, R. S. Duman, D. S. Russell and C. D'Sa, Repeated Unpredictable Stress and Antidepressants Differentially Regulate Expression of the Bcl-2 Family of Apoptotic Genes in Rat Cortical, Hippocampal, and Limbic Brain Structures, Neuropsychopharmacology, 2007, 33, 1545-1558.

57 J. Yang, X. Liu, K. Bhalla, C. N. Kim, A. M. Ibrado, J. Cai, T. I. Peng, D. P. Jones and X. Wang, Prevention of Apoptosis by Bcl-2: Release of Cytochrome $\mathrm{c}$ from Mitochondria Blocked, Science, 1997, 275, 1129-1132.

58 R. M. Kluck, E. Bossy-Wetzel, D. R. Green and D. D. Newmeyer, The Release of Cytochrome $c$ from Mitochondria: A Primary Site for Bcl-2 Regulation of Apoptosis, Science, 1997, 275, 1132-1136.

59 P. J. Lucassen, M. B. Müller, F. Holsboer, J. Bauer, A. Holtrop, J. Wouda, W. J. G. Hoogendijk, E. R. D. Kloet and D. F. Swaab, Hippocampal apoptosis in major depression is a minor event and absent from subareas at risk for glucocorticoid overexposure, Am. J. Pathol., 2001, 158, 453-468.

60 H. Dudek, S. R. Datta, T. F. Franke, M. J. Birnbaum, R. Yao, G. M. Cooper, R. A. Segal, D. R. Kaplan and M. E. Greenberg, Regulation of Neuronal Survival by the Serine-Threonine Protein Kinase Akt, Science, 1997, 275, 661-665.

61 R. Ma, N. Xiong, C. Huang, Q. Tang, B. Hu, J. Xiang and G. Li, Erythropoietin protects PC12 cells from $\beta$-amyloid an-35- $^{-}$ induced apoptosis via PI3K/Akt signaling pathway, Neuropharmacology, 2009, 56, 1027-1034.

62 Y. Q. Xu, L. Long, J. Q. Yan, L. Wei, M. Q. Pan, H. M. Gao, P. Zhou, M. Liu, C. S. Zhu, B. S. Tang and Q. Wang, Simvastatin induces neuroprotection in 6-OHDA-lesioned PC12 via the PI3K/Akt/caspase 3 pathway and antiinflammatory responses, CNS Neurosci. Ther., 2013, 19, 170-177.

63 W. Zhang, R. Wang, S. F. Han, L. Bu, S. W. Wang, H. Ma and G. L. Jia, $\alpha$-Linolenic acid attenuates high glucose-induced apoptosis in cultured human umbilical vein endothelial cells via PI3K/Akt/eNOS pathway, Nutrition, 2007, 23, 762770.

64 H. Gao, P. Yan, S. Zhang, H. Huang, F. Huang, T. Sun, Q. Deng, Q. Huang, S. Chen, K. Ye, J. Xu and L. Liu, LongTerm Dietary Alpha-Linolenic Acid Supplement Alleviates Cognitive Impairment Correlate with Activating Hippocampal CREB Signaling in Natural Aging Rats, Mol. Neurobiol., 2016, 53, 4772-4786.

65 S. Finkbeiner, CREB couples neurotrophin signals to survival messages, Neuron, 2000, 25, 11-14.

66 Y. Wang, J. Zhang, M. Han, B. Liu, Y. Gao, P. Ma, S. Zhang, Q. Zheng and X. Song, SMND-309 promotes neuron survival through the activation of the PI3K/Akt/CREB-signalling pathway, Pharm. Biol., 2016, 54, 1982-1990. 